
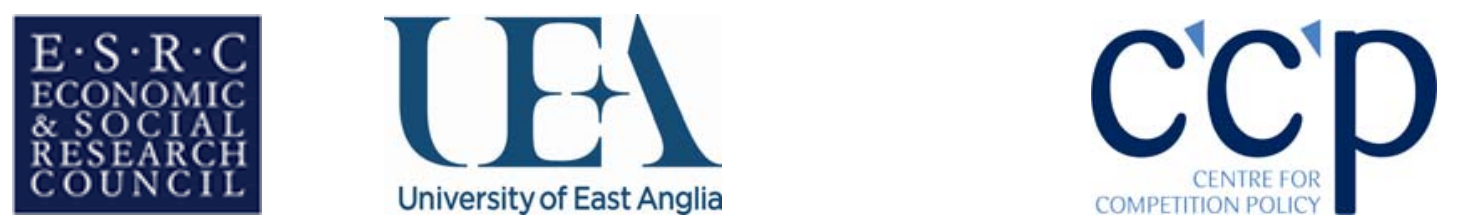

\title{
Unilateral versus Coordinated Effects: Comparing the Impact on Consumer Welfare of Alternative Merger Outcomes
}

\author{
Matthew Olczak
}

\author{
CCP Working Paper 10-3
}

\begin{abstract}
:
The nature of tacitly collusive behaviour often makes coordination unstable, and this may result in periods of breakdown, during which consumers benefit from reduced prices. This is allowed for by adding demand uncertainty to the Compte et al. (2002) model of tacit collusion amongst asymmetric firms. Breakdowns occur when a firm cannot exclude the possibility of a deviation by a rival. It is then possible that an outcome with collusive behaviour, subject to long/frequent break downs, can improve consumer welfare compared to an alternative with sustained unilateral conduct. This is illustrated by re-examining the Nestle/Perrier merger analyzed by Compte et al., but now also taking into account the potential for welfare losses arising from unilateral behaviour.

October 2009
\end{abstract}

JEL Classification Codes: L13, L41

Keywords: Tacit collusion, collective dominance, coordinated effects, unilateral effects, merger policy.

\section{Acknowledgements:}

The initial motivation for this paper arose from a number of discussions with Steve Davies and it has also benefited considerably from his subsequent advice. I am also extremely grateful to Morten Hviid and Chris Wilson for the numerous suggestions they have provided. In addition, I would like to thank 
Zhijun Chen, Luke Garrod and Bruce Lyons. The support of the Economic and Social Research Council (UK) is gratefully acknowledged.

\section{Contact details:}

Economics and Strategy Group, Aston Business School, Aston University, Birmingham, B4 7ET, UK. m.olczak@aston.ac.uk 


\title{
Unilateral versus coordinated effects: comparing the impact on consumer welfare of alternative merger outcomes*
}

\author{
Matthew Olczak ${ }^{\dagger}$
}

October 2009

\begin{abstract}
The nature of tacitly collusive behaviour often makes coordination unstable, and this may result in periods of breakdown, during which consumers benefit from reduced prices. This is allowed for by adding demand uncertainty to the Compte et al. (2002) model of tacit collusion amongst asymmetric firms. Breakdowns occur when a firm cannot exclude the possibility of a deviation by a rival. It is then possible that an outcome with collusive behaviour, subject to long/frequent break downs, can improve consumer welfare compared to an alternative with sustained unilateral conduct. This is illustrated by re-examining the Nestle/Perrier merger analyzed by Compte et al., but now also taking into account the potential for welfare losses arising from unilateral behaviour.
\end{abstract}

JEL Classification codes: L13, L41

Keywords: Tacit collusion, collective dominance, coordinated effects, unilateral effects, merger policy

${ }^{*}$ The initial motivation for this paper arose from a number of discussions with Steve Davies and it has also benefited considerably from his subsequent advice. I am also extremely grateful to Morten Hviid and Chris Wilson for the numerous suggestions they have provided. In addition, I would like to thank Zhijun Chen, Luke Garrod and Bruce Lyons. The support of the Economic and Social Research Council (UK) is gratefully acknowledged.

${ }^{\dagger}$ Economics and Strategy Group, Aston Business School, Aston University, Birmingham, B4 7ET, UK. m.olczak@aston.ac.uk 


\section{Introduction}

There are two main theories of harm under which competition authorities intervene in a horizontal merger investigation: unilateral and coordinated effects. Unilateral effects arise from an individual incentive for the merged entity to raise prices post-merger whereas coordinated effects arise if the merger results in an increased likelihood of tacit collusion (see Ivaldi et al. (2003a) and (2003b)). Recent theoretical advances have significantly increased our understanding of the circumstances under which coordinated effects are likely to occur. Previously, most attention had been on the role of firm numbers. A reduction in the number of (symmetric) players can be shown to increase the likelihood of tacit collusion ${ }^{1}$. This suggests any merger will enhance the possibility of collusive behaviour to some extent. However, recently Compte et al. (2002) and Kühn (2004) for example, have highlighted the crucial role of symmetry between firms, with the clear consensus that increased asymmetries reduce the likelihood of collusion.

Since symmetric outcomes are most conducive to tacit collusion whereas asymmetric outcomes may result in a market leader with a dominant position, there is a potential important trade-off between the two (see also Motta et al. 2003). Acknowledging this, Röller and Mano (2006, p.22) nevertheless suggest that a merger which disrupts coordination but enhances single dominance (unilateral effects) may be pro-competitive since:

"...it is preferable that any coordination is by only a subset of firms (i.e. the merging parties) rather than all firms (tacitly)."

This view is consistent with the collusive behaviour described in models with demand certainty, such as Compte et al. (2002). Here, deviations from collusive behaviour are perfectly observable and a punishment mechanism is required to prevent such deviations; however, as long as firms are sufficiently patient no deviation will occur in equilibrium and the monopoly price can be sustained.

Assessing the likelihood of collusive behaviour in this way means that

\footnotetext{
${ }^{1}$ See for example Ivaldi et al. (2003a).
} 
comparisons between a potentially collusive outcome and an outcome where unilateral behaviour is expected involve contrasting the likelihood that firms are sufficiently patient with an expected price resulting from unilateral behaviour. This would appear to be an extremely difficult comparison to make. Furthermore, we believe that such models of collusive behaviour fail to take into account the likely nature of tacit collusion. Tacit collusion is substantially different from hard-core cartels which (at least on the evidence of detected cartels) typically involve sophisticated organisational structures with frequent communication and, complex monitoring and enforcement mechanisms $^{2}$. As Harrington (2006, p.2) argues:

"...hard-core cartels meet frequently and regularly. Firms are then continually running the risk of discovery and they presumably do so because these meetings generate more profitable outcomes than tacit collusion.'

In contrast, tacit collusion is often likely to be less stable i.e. subject to periods of breakdown and/or result in lower prices than are achievable through explicit collusion. Therefore, in this paper we allow for the possibility of breakdowns in a model of tacit collusion by introducing demand uncertainty to the Compte et al. model (2002) described in more detail below. This follows the literature initiated by Green and Porter (1984) where unobserved demand fluctuations are used as a means to introduce a lack of transparency. Once the market is not fully transparent deviations are no longer perfectly observable. As was first shown by Green and Porter (1984) in a Cournot setting, once demand uncertainty is introduced, collusion can breakdown. Tirole (1988) illustrates the Green and Porter mechanism in a simpler Bertrand price competition setting with two symmetric firms, homogeneous products and no capacity constraints ${ }^{3}$. In such models collusion breaks down because firms cannot always distinguish between a rival deviation and low industry demand. Sufficiently long 'punishment' periods are required when industry demand appears low in order to deter deviations from collusive behaviour. Without these 'punishment' periods deviations would

\footnotetext{
${ }^{2}$ See for example Harrington (2006).

${ }^{3}$ See also Ivaldi et al. (2003a).
} 
be profitable because the resulting reduced sales for the non-deviating firms are consistent with low industry demand and would go unpunished.

Once breakdowns are taken into account, it is no longer always true that an outcome subject to tacit collusion results in lower consumer welfare than an alternative with unilateral behaviour. It is then possible to make meaningful comparisons between such alternative outcomes. In section 5, this is illustrated by re-examining the Nestle/Perrier merger analyzed by Compte et al. (2002). This case demonstrates the benefits adopting a more realistic view of tacit collusion can have merger decisions.

The approach adopted in this paper also has implications for the merger simulation methodology which attempts to estimate the predicted price effect of a merger. Previously this literature has been confined to assessing unilateral effects (see for example Werden and Froeb (1994) and Nevo (2000)) but recent attempts (discussed in section 6) have been made to also consider the possibility of collusive behaviour. We demonstrate that once demand uncertainty is introduced, direct comparisons between outcomes can be made, crucially including comparisons between outcomes where different theories of harm (i.e. unilateral or collusive behaviour) are expected.

The remainder of the paper proceeds as follows: firstly, some initial background on the Nestle/Perrier merger and the Compte et al. (2002) findings help motivate the rest of the paper. Sections 2-4 then provide a detailed description of the model, here breakdowns in collusive behaviour are assumed to occur when a firm cannot exclude the possibility of a deviation by a rival. Section 4.2 provides some general results on the circumstances under which this implies collusion will breakdown and the frequency with which this can be expected to occur. Breakdowns are shown to be most likely to occur when it is possible that the smallest firm has deviated. Section 5 then applies the model to the Nestle/Perrier merger. Here it is first shown that, as expected, absent remedies collusive behaviour is unlikely to occur postmerger, but nevertheless a significant unilateral effect occurs. The resulting consumer welfare is then compared with alternative remedy outcomes where collusive behaviour is expected to occur. Crucially, the comparisons depend upon the extent to which demand fluctuations reduce transparency and make 
collusion subject to breakdowns.

\section{The Nestle/Perrier merger}

The 1992 Nestle/Perrier merger was the first EC merger decision in which a remedy was imposed in order to 'prevent' coordinated effects. The proposed merger would have created a merged entity with a market share of over $50 \%$ and the nearest rival's share below $25 \% 4$. It is clear from the case report that, without any commitments offered by the merging parties, the merger would have been blocked on single dominance grounds ${ }^{5}$. In order to encourage early clearance, the parties offered a divestment (henceforth Remedy 1). This involved the sale of Perrier's Volvic brand and capacity to BSN, the main rival to Nestle and Perrier. However, the Commission argued that such a divestment would be conducive to tacit collusion and therefore would be blocked on the grounds of collective dominance (i.e. coordinated effects). In response, the parties agreed to also divest additional brands and capacity to a 3 rd party ${ }^{6}$ (henceforth Remedy 2). Table 1 describes the resulting capacity levels $\left(k_{i}\right)$ for the main players in the industry ${ }^{7}$ under the four alternative outcomes.

\footnotetext{
${ }^{4}$ M.190 Nestle/Perrier (1992), para 133.

${ }^{5}$ M.190 Nestle/Perrier (1992), para 132.

${ }^{6}$ i.e. to a firm other than BSN.

${ }^{7}$ In addition to these main players a fringe of small, dispersed local suppliers are ignored by Compte et al. (2002, p.18) as, in its merger decision, the EC did not regard these fringe players as a substantial competitive force.
} 
Table 1: Nestle/Perrier merger capacity distributions

\begin{tabular}{c|cccc}
\hline & $\begin{array}{c}\text { Pre } \\
\text { (Actual } \\
\text { pre merger) }\end{array}$ & $\begin{array}{c}\text { Post } \\
\text { (Post merger } \\
\text { absent } \\
\text { remedies) } \\
\text { (Parties }\end{array}$ & $\begin{array}{c}\text { Remedy 1 } \\
\text { proposed } \\
\text { remedy) } \\
k_{i}\end{array}$ & $\begin{array}{c}\text { Remedy 2 } \\
\text { (Accepted } \\
\text { remedy) }\end{array}$ \\
\hline Nestle & 1800 & & & $k_{i}$ \\
Perrier & 13700 & & & \\
Nestle/Perrier & & 15500 & 9800 & 6800 \\
BSN & 1800 & 1800 & 7500 & 7500 \\
New Player & & & & 3000 \\
\hline Total & 17300 & 17300 & 17300 & 17300 \\
\hline$\delta^{*}($ Compte et al., 2002$)$ & 0.59 & 0.75 & 0.5 & 0.61 \\
\hline Static NE average prices & 0.53 & 0.88 & 0 & 0 \\
\hline
\end{tabular}

All capacity levels are measured in million litres and the total market size was estimated to be 5250 million litres $^{8}$. Compte et al. (2002) model Bertrand-Edgeworth competition with asymmetric capacities as a repeated game. The likelihood of collusion is measured by solving for the common critical discount factor $\left(\delta^{*}\right)$ above which collusion is sustainable i.e. as long as firms are sufficiently patient. The penultimate row of Table 1 reports this critical discount factors for the four outcomes. This demonstrates that the outcome most conducive to collusion would be Remedy 1 (the merger plus only the transfer to BSN). Since both firms have capacity in excess of the market demand, this outcome results in a perfectly symmetric duopoly ${ }^{9}$. The outcome least conducive to collusion is the merger without remedy (Post). Here the merged entity has sufficient capacity to tempt deviations from the

\footnotetext{
${ }^{8}$ Compte et al. (2002) p.18, based upon sales figures reported in the EC merger decision.

${ }^{9}$ Because both firms can supply the entire market demand in the Compte et al. model they share the market equally at the collusive price and, in addition, can steal the entire market demand by deviating.
} 
collusive agreement, whilst BSN's punishment capability is limited by its low capacity. Thus, Compte et al. argue that the accepted remedy placed too much emphasis on creating a third main player and too little attention to the role of symmetry in enhancing the likelihood of collusion. Despite reducing the likelihood of collusion compared to the parties' initial proposal (Remedy 1 ), the accepted remedy (Remedy 2) makes collusion more likely than would follow the initial merger absent any remedy.

In the current paper it is argued that assessing the merger solely in terms of the potential for collusion only captures part of the story. In particular, a move from the pre- to the post-merger outcome may reduce the likelihood of collusion, but still result in a considerable unilateral effect. To illustrate, the final row of Table 1 reports calculations of the average prices that would result from non-coordinated behaviour in each of the four possible outcomes assuming for the moment a fixed level of demand ${ }^{10}$. This clearly demonstrates that, while the post-merger outcome may be preferable in terms of a reduced risk of collusion, it may nevertheless result in consumer harm due to noncoordinated behaviour. In this case the rejected early remedy offer by the parties, increasing the number of possible outcomes, highlights this conflict between theories of harm particularly starkly. However, as suggested above, this is illustrative of a far more general trade-off between unilateral and coordinated effects.

\section{Model}

\subsection{Notation and assumptions}

The modeling assumptions made are similar to those used by Compte et al. (2002), with the additional introduction of demand uncertainty. In each period demand is perfectly inelastic and made up of $\tilde{M}$ infinitesimal buyers with a reservation price equal to $1 . \tilde{M}$ is the realisation of demand in any period, with $\tilde{M}$ independently drawn and uniformly distributed between $M-u$ and $M+u$ (where $M>u>0$ ). There are $n$ firms $(n \geq 2)$ producing a homo-

\footnotetext{
${ }^{10}$ See Appendix A.3 for the derivation of these prices.
} 
geneous product with constant marginal costs $(c)$, where $c$ is normalized to zero. Each firm has a production capacity of $\hat{k}_{i}$ and without loss of generality denote $\hat{k}_{n} \geq \hat{k}_{n-1} \geq \ldots \geq \hat{k}_{1}$. Since $\max \{\tilde{M}\}=M+u$ clearly any firm's capacity above $M+u$ is redundant. Therefore, henceforth we simply denote $k_{i}=\min \left\{\hat{k}_{i}, M+u\right\} . K$ will be used to denote total industry capacity i.e. $\sum_{i} k_{i} \equiv K$ and $K_{-j}$ is the total capacity of $j$ 's rivals i.e. $\sum_{i \neq j} k_{i} \equiv K_{-j}$.

\subsection{Demand rationing and sales}

Each period total demand $(\tilde{M})$ is rationed ${ }^{11}$ such that:

- Amongst a group of firms setting equal prices (and $p \leq 1$ ) consumers are assumed to divide themselves in proportion to a firm's share of the aggregate group capacity ${ }^{12}$. So, for example when all firms set the same price firm $i$ 's share of demand is $k_{i} / K$.

- Consumers are assumed to visit the lowest priced firm(s) in the market first, only if this group of firm(s) cannot supply the entire demand realisation $(\tilde{M})$ due to capacity constraints do the higher priced firms receive positive demand ${ }^{13}$.

The sales of firm $i$ for a given capacity arrangement will be denoted as $S_{i}$. Following the demand rationing scheme the sales of firm $i$ can be derived as follows:

\footnotetext{
${ }^{11}$ Since demand is perfectly inelastic and all consumers have the same reservation price the distinction between proportional and surplus maximizing rationing rules (see for example Vives, 1999, pp. 124-6) does not apply in this case.

${ }^{12}$ In Compte et al., with demand fixed at $M$, a firm's relevant capacity is defined as the $\min \left\{k_{i}, M\right\}$. At equal prices demand is then assumed to be rationed in proportion to these capacities, and this is shown to be an optimal allocation under collusive behaviour. Introducing demand uncertainty means that this definition of relevant capacity will often depend upon the precise realisation of demand. Therefore, here instead, we use each firm's share of total capacity (where a firm's individual capacity is at most the maximum demand realisation: $M+u$ (see section 2.1)).

${ }^{13}$ This means that consumers are fully informed of the cheapest supplier whilst, as discussed in section 4.1, firms are unaware of their rivals' pricing decisions. This can be justified by allowing secret offers to be made to consumers below a posted price (see also footnote 19, p. 13).
} 


\section{When $i$ sets the lowest price in the market}

As the lowest priced firm, firm $i$ can make expected sales (denoted $S_{i}^{L}$ ) up to full capacity provided industry demand is sufficiently high i.e. $S_{i}^{L}=$ $\min \left\{k_{i}, \tilde{M}\right\}$ (where as explained above $k_{i}=\min \left\{\hat{k}_{i}, M+u\right\}$ ). Therefore, taking into account the assumed uniform distribution of demand and denoting the probability density function $f(x)$ :

$$
S_{i}^{L}= \begin{cases}k_{i} & \text { if } k_{i} \leq M-u \\ \int_{M-u}^{k_{i}} x f(x) d x+\int_{k_{i}}^{M+u} k_{i} f(x) d x & \\ =\left(2 k_{i}(M+u)-k_{i}{ }^{2}-(M-u)^{2}\right) / 4 u & \text { if } k_{i}>M-u\end{cases}
$$

\section{When $i$ sets the highest price in the market}

As the highest priced firm in the market firm $i$ 's expected sales (denoted $S_{i}^{H}$ ) are positive only if all other firms have sold their full capacity and there is demand remaining. Therefore $S_{i}^{H}=0$ if $K_{-i} \geq M+u$ and in contrast if there is demand remaining then $S_{i}^{H}=\min \left\{\left(\tilde{M}-K_{-i}\right), k_{i}\right\}$. In this paper we will focus on cases where overall capacity is such that the total market demand can always be supplied (i.e. $K>M+u)^{14}$. Formally in this case $S_{i}^{H}=\int_{K_{i}}^{M+u}\left(x-K_{-i}\right) f(x) d x$ and therefore since demand is assumed to be uniformly distributed:

$$
S_{i}^{H}= \begin{cases}\left(M+u-K_{-i}\right)^{2} / 4 u & \text { if } M-u<K_{-i}<M+u \\ M-K_{-i} & \text { if } K_{-i} \leq M-u\end{cases}
$$

As long as $K_{-i}<M+u$, even as the highest priced firm, firm $i^{\prime} s$ expected sales are positive $\left(S_{i}^{H}>0\right)$.

\footnotetext{
${ }^{14}$ This is the appropriate case for the Nestle/Perrier merger (see Table 1). In addition, see Lemma 3 below which shows that, under the collusive scheme considered here, this is a necessary condition for sustainable collusion. However, $S_{i}^{H}$ can also be rewritten for $K<M+u$ by taking into account that for some demand realisations even the highest priced firm is capacity constrained.
} 


\section{Static Nash Equilibrium}

Before proceeding to the model of collusive behaviour in section 4 , here the static Nash equilibrium (NE) is described. Depending upon the specific capacity distribution this involves either pure or mixed pricing strategies. The precise conditions are provided in the following lemma:

Lemma 1. A pure strategy NE exists:

a. If $K \leq M-u$. The only equilibrium of the game involves pricing at the consumers' reservation price $\left(p_{i}=1 \forall i\right)$ with firms selling their entire capacity $\left(\pi_{i}^{N E}=k_{i} \forall i\right)$.

b. If $K_{-n} \geq M+u$. The only equilibrium of the game involves marginal cost pricing $\left(p_{i}=0 \forall i\right)$ and therefore $\pi_{i}^{N E}=0 \forall i$.

For $K>M-u$ and $K_{-n}<M+u$ there is no equilibrium in pure strategies.

Proof: see Appendix A.1

If total capacity is sufficiently low such that the market demand can never be supplied, then there is no effective competition and firms can always sell their full capacity at the monopoly price (Lemma 1a). In contrast, if the $n-1$ smaller firms (i.e. all firms apart from the largest) are together sufficiently large to always be able to supply the market demand, then competition results in price equal to marginal cost (Lemma 1b) as in standard homogeneous product Bertrand competition. This arises because here any subset of the $n-1$ firms can serve the entire market demand, meaning a higher priced firm makes no sales. ${ }^{15}$

As shown in detail in Appendix A.2, for the capacity levels described in Lemma 1 where there is no pure strategy NE, a mixed strategy Nash equilibrium will be shown to exist ${ }^{16}$ for a range of parameter values (see Proposition 1). The equilibrium closely resembles the standard Bertrand

\footnotetext{
${ }^{15}$ Hviid (1991) provides conditions for the existence of the pure strategy NE in Lemma 1a) with an elastic demand curve. In addition, the equilibrium in Lemma b) is shown to not exist in this setting.

${ }^{16}$ The existence of a mixed strategy Nash equilibrium follows from Dasgupta and Maskin (1986a, pp.7-17 and 1986b, pp.27-9).
} 
Edgeworth mixed strategy $\mathrm{NE}^{17}$, with now demand uncertainty introduced, and the underlying intuition is also very similar. The largest firm's (firm $n$ 's) rivals together cannot always supply the entire market demand $\left(K_{-n}<\right.$ $M+u)$. Consequently from (2), even if it is the highest priced firm, in expectation firm $n$ makes positive sales (equal to $S_{n}^{H}$ ). The profits from such sales are clearly highest by pricing at the consumers' reservation price. Firm $n$ will therefore only be willing to undercut its rivals and increase its sales if this results in profits above this level. This enables us to define the lowest price firm $n$ will ever charge $\left(p_{n}^{\min }\right)$. It is then necessary to consider the remaining smaller firms' incentives to price below $p_{n}^{\text {min }}$. In the duopoly case this is straightforward, firm 1 has no incentive to ever price below $p_{n}^{\text {min }}-\epsilon$ ( $\epsilon>0$ but small). For $n>2$ the mixed strategy NE is in general considerably more complex. However, if the largest firm's rivals are guaranteed to sell their full capacity at $p_{n}^{m i n}-\epsilon$ (i.e. $K_{-n} \leq M-u$ ), then again there is no incentive to price below this level. In the case of $n>2$ we will therefore restrict our attention to cases for which ${ }^{18} K_{-n} \leq M-u$ (for the application to the Nestle/Perrier merger in section 5 this does not prove too restrictive). The above intuition allows us to derive the expected profits which result in equilibrium (where $S_{i}^{L}$ and $S_{i}^{H}$ are defined in section 2.2):

Proposition 1. For $K>M-u$ and $K_{-n}<M+u$, if either: $n=2$, or $n>2$ and $K_{-n} \leq M-u$, there is a mixed strategy Nash equilibrium with expected profits given by $\pi_{i}^{N E}=\left(S_{n}^{H} / S_{n}^{L}\right) S_{i}^{L}$.

Proof: see Appendix A.2

Finally, the static NE profits given in Proposition 1 can be used to find the resulting consumer welfare. From the demand function, total welfare each period is equal to $\tilde{M}$ and made up of $C S+\sum_{i=1}^{n} \pi_{i}$. Expected demand each period is $M$ and therefore the expected consumer surplus from the static Nash equilibrium $\left(C S_{N E}\right)$ is: $M-\sum_{i=1}^{n} \pi_{i}^{N E}$.

\footnotetext{
${ }^{17}$ See Appendix A.3 and Fonseca and Normann (2008). See also Gal-Or (1984) which allows for demand uncertainty in a model with symmetric firms.

${ }^{18}$ In contrast, if $K_{-n}>M-u$, all firms apart from the largest would have an incentive to compete below $p_{n}^{\text {min }}$ in order to gain additional sales.
} 


\section{Collusive equilibrium}

\subsection{Order of moves}

In order to allow for collusive behaviour, Bertrand-Edgeworth price competition will be modelled as an infinitely repeated game. Firms discount future periods with a common discount factor $(\delta)$, where $0<\delta<1$. In each period firms simultaneously set prices without knowing the realisation of demand $(\tilde{M})$. The realisation of demand always remains unknown, however, all firms know the range of demand fluctuations $(u)$, and that demand is uniformly distributed over this range. In addition, all individual capacity levels are common knowledge. In each period firms observe only their own sales. The pricing decisions and sales made by rival firms remain unobserved throughout the game. However, as will now be discussed in more detail, firms can make inferences about rivals' pricing decisions from their own sales.

\subsection{Breakdown in collusion}

Section 4.3 will provide conditions which ensure that actual deviations from collusive behaviour are unprofitable. However, because of the lack of transparency caused by demand uncertainty it may nevertheless appear as though a deviation has occurred. Therefore, in order to capture the potential instability of tacit collusion (see section 1) we focus on a specific collusive scheme by making the following key assumption:

ASSUMPTION: a switch from collusive to non-collusive behaviour occurs in the next period if, from observing its own sales, any firm cannot exclude the possibility that a rival has deviated from collusive behaviour. If so, all firms then commence punishment behaviour for at least one period, during which they revert to static Nash equilibrium behaviour.

In order to illustrate how a firm can make inferences about a rival's behaviour from its own sales consider the following simple numeric example: 


\section{Illustrative numerical example of the probability of a breakdown in collusion:}

Assume a duopoly in which each firm's capacity is $k=24$ and demand fluctuations are such that $M-u=10$ and $M+u=30$. Under collusive behaviour the two firms share equally the total demand and therefore make sales of between 5 and 15. If one firm deviates from the collusive behaviour the non-deviating firm makes sales of between 0 and 6 depending upon the realisation of demand. Therefore collusive sales of 6 or less are also consistent with a rival firm having deviated. Thus, despite no deviation actually occurring, under the collusive scheme sales of 6 or below cause collusion to breakdown. Collusive sales are 6 or lower when $\tilde{M} \leq 12$ and given the uniform distribution of demand this occurs with probability 0.1 .

We can now derive an expression for the probability collusion breaks down for general demand and capacity levels, and for $n \geq 2$. Based on the assumption described above, we need to consider the likelihood that firm $i$ 's sales during a period where all firms adopt collusive behaviour are such that a rival could have deviated. Let $B_{i}$ be the probability that sales are sufficiently low for this to be a possibility. Firstly, denote the sales firm $i$ receives following a rival $(j)$ 's deviation ${ }^{19}$ as $S_{i}^{R D}$. Firm $i$ can rule out the possibility of a rival deviated if its collusive sales $\left(S_{i}^{C}\right)$ are such that: $S_{i}^{C}>\max S_{i}^{R D}$ where $\max S_{i}^{R D}$ is the maximum possible sales $i$ can receive following a deviation by $j$ (i.e. $S_{i}^{R D}$ evaluated at $\tilde{M}=M+u$ ). Analogously, it is possible that a rival has deviated if: $S_{i}^{C} \leq \max S_{i}^{R D}$ and therefore:

$$
B_{i}=\operatorname{Prob}\left(S_{i}^{C} \leq \max S_{i}^{R D}\right)
$$

We can initially consider two extreme cases for the probability $B_{i}$. Lemma 2 provides a sufficient condition for collusion to never breakdown:

\footnotetext{
${ }^{19} \mathrm{By}$ undercutting the collusive price firm $j$ will sell to either its full capacity or the market demand (which ever is smaller). Partial deviations can be ruled out by prohibiting price discrimination and refusal to supply. As buyers are assumed to be fully informed they can therefore buy from the cheaper firm subject to capacity.
} 
Lemma 2. Collusion will not breakdown $\left(B_{i}=0 \forall i\right)$ when each of the firms' capacity levels covers the maximum market demand i.e $M+u \leq k_{1}$.

The intuition behind Lemma 2 is extremely simple, if a firm can supply the entire market, even when demand is at its highest, any deviation leaves the non-deviating firms with no sales $\left(\max S_{i}^{R D}=0\right)$. In contrast, in any collusive period all firms make positive sales ${ }^{20}$. Therefore, there is no inference problem and collusion only breaks down following an actual deviation (which will not occur along the equilibrium path (see section 4.3)). Here, in effect the capacity constraints are redundant and, as in the Tirole (1988) model described in the introduction, a positive probability of zero demand is needed for there to be an inference problem ${ }^{21}$.

In contrast, Lemma 3 shows that under certain circumstances collusion will always breakdown ${ }^{22}$ :

Lemma 3. Collusion will always breakdown $\left(B_{i}=1 \forall i\right)$ if total capacity does not exceed the maximum market demand $(K \leq M+u)$.

If total capacity is low, even if firm $j$ deviates, the remaining firms can sell to full capacity in high demand states. These firms can never sell more than their capacity and therefore any collusive period is also consistent with demand being high and firm $j$ having deviated. Consequently, following the collusive scheme, collusion will always breakdown after just a single period.

We can now obtain a general expression for the probability $B_{i}$ which, from Lemmas 2 and 3, will result when $K>M+u$ and $k_{j}<M+u$ for some firm $j$. During collusive behaviour all firms set an equal price and therefore from section 2.2: $S_{i}^{C}=\min \left\{k_{i},\left(k_{i} / K\right) \tilde{M}\right\}$, which since $K>M+u$ can be written as $S_{i}^{C}=\left(k_{i} / K\right) \tilde{M}$. Likewise, $\max S_{i}^{R D}=\left(M+u-k_{j}\right)\left(k_{i} / K_{-j}\right)$ and

\footnotetext{
${ }^{20}$ During collusive behaviour all firms set an equal price and therefore from section 2.2: $S_{i}^{C}=\min \left\{k_{i},\left(k_{i} / K\right) \tilde{M}\right\}$. Since industry demand is always positive $(M-u>0)$ $S_{i}^{C}>0 \forall \tilde{M}$.

${ }^{21}$ See Tirole (1988) pp. 262-263.

${ }^{22}$ To see this first note that when $K \leq M+u$, if demand is at its highest all firms can sell their full capacity despite a rival deviation $\left(\max S_{i}^{R D}=k_{i}\right)$. However, it must be the case that $S_{i}^{C} \leq k_{i}$ and so from (3) $B_{i}=0$.
} 
therefore (3) can be written as:

$$
B_{i}=\operatorname{Prob}\left(\left(\frac{k_{i}}{K}\right) \tilde{M} \leq\left(M+u-k_{j}\right)\left(\frac{k_{i}}{K_{-j}}\right)\right)
$$

Rearranging (4):

$$
B_{i}=\operatorname{Prob}\left(\tilde{M} \leq\left(M+u-k_{j}\right)\left(\frac{K}{K_{-j}}\right)\right)
$$

Lemma 4. It follows from (5) that:

- $B_{i}>0$ iff $M-u<\left(M+u-k_{j}\right)\left(K / K_{-j}\right)$

Therefore $B_{i}=0$ if the size of demand fluctuations are sufficiently low and rival(s) have capacity sufficiently close to the maximum market demand.

- The probability firm i receives collusive sales such that it cannot rule out a deviation by a rival is increasing in the size of demand fluctuations $\left(\partial B_{i} / \partial u>0\right)$.

Lemma 4 strengthens the necessary condition for $B_{i}>0$ established by Lemma 2. Appendix B.1 then shows that, holding $K$ fixed, the right-hand side of (5) is decreasing in $k_{j}$ and therefore:

Lemma 5. The level of $\tilde{M}$ below which it is not possible for firm $i$ to exclude a rival deviation is highest for a possible deviation by its smallest rival.

Intuitively, deviations by larger firms steal more of the total demand, and sales consistent with this are less likely to arise when all firms adopt collusive behaviour. As $\tilde{M}$ is assumed to be uniformly distributed between $M-u$ and $M+u$ from (5):

Proposition 2. The probability firm $i$ receives collusive sales such that it cannot rule out a deviation by a rival is given by:

$$
B_{i}=\frac{\left(M+u-k_{l}\right)\left(K / K_{-l}\right)-(M-u)}{2 u}
$$

Where from Lemma $5: l=\min \{1, \ldots, n\}$ subject to $l \neq i$. 
It follows from Lemma 5 that for $n>2 B_{n}=B_{n-1}=\cdots=B_{2}$. In addition, Appendix B.2 shows that $B_{2}>B_{1}$ if $k_{2}$ is strictly greater than $k_{1}$, and therefore:

Proposition 3. When all firms adopt collusive behaviour, it is most likely that the largest $n-1$ firms receive sales consistent with a deviation by the smallest firm.

Proof: see Appendix B.2

The intuition follows from Lemma 5, it is easier for the smallest firm to exclude a deviation by a larger rival since any such deviation has a considerable effect on the residual demand and therefore the smallest firms sales. It is therefore unlikely that the smallest firm's collusive sales will fall below this level. In contrast, it is more difficult for the larger firms to exclude the possibility of a deviation by the smallest firm. As the degree of size inequality between $k_{1}$ and $k_{2}$ falls this difference is reduced.

Proposition 3 implies that there may be circumstances in which all firms apart from the smallest receive sales suggesting a possible deviation and therefore switch to punishment behaviour. As outlined in the earlier assumption, it will be assumed if this situation arises that the smallest firm also immediately switches to punishment behaviour. This is consistent with the smallest firm inferring that its rivals will switch. Then, because the punishment phase involves reversion to the static Nash equilibrium the best-reply for the smallest firm is also to switch to punishment behaviour (see section 6 for more discussion). Therefore henceforth, the probability of a breakdown occurring during a collusive period will be denoted $B^{*}$ where $B^{*}=\max \left\{B_{i}\right\}$, from Proposition 3 we know that $B^{*}=B_{n}$.

\subsection{Length of punishment phase}

The previous section specified the probability of breakdowns in collusive behaviour as a result of the possibility of deviations occurring. The next step is to determine the appropriate length for punishment phases to ensure that actual deviations from collusive behaviour do not occur. 
Following the standard approach ${ }^{23}$, the expected discounted profit for firm $i$ from collusive behaviour $\left(V_{i}^{C}\right)$, taking into account that collusion breaks down with probability $B^{*}$, can be written as:

$$
V_{i}^{C}=\pi_{i}^{C}+\left(1-B^{*}\right)\left(\delta V_{i}^{C}\right)+B^{*}\left(\delta+\ldots+\delta^{T_{i}}\right) \pi_{i}^{N E}+\left(\delta^{T_{i}+1} V_{i}^{C}\right)
$$

Where $\pi_{i}^{C}$ is firm $i$ 's profit during collusive periods. If collusion does breakdown a $T_{i}$ period punishment phase commences during which we assume firms revert to the static Nash equilibrium behaviour and thus receive $\pi_{i}^{N E}$. Then after $T_{i}$ periods collusion resumes for at least one period. Rearranging (6):

$$
V_{i}^{C}=\frac{\pi_{i}^{C}+B^{*} \pi_{i}^{N E}\left(\delta+\ldots+\delta^{T_{i}}\right)}{1-\left(1-B^{*}\right) \delta-B^{*} \delta^{T_{i}+1}}
$$

Collusion is sustainable for firm $i$ if and only if:

$$
V_{i}^{C} \geq \pi_{i}^{D}+\left(\delta+\ldots+\delta^{T_{i}}\right) \pi_{i}^{N E}+\delta^{T_{i}+1} V_{i}^{C}
$$

Where $\pi_{i}^{D}$ represents firm $i$ 's profit from deviating from the collusive agreement. This is then followed by a definite $T$ period punishment phase before collusion resumes. Rearranging (8):

$$
V_{i}^{C} \geq \frac{\pi_{i}^{D}+\left(\delta+\ldots+\delta^{T_{i}}\right) \pi_{i}^{N E}}{1-\delta^{T_{i}+1}}
$$

Substituting in for $V_{i}^{C}$ from (7) and rearranging:

$$
\delta^{T_{i}+1} \leq \frac{\delta\left(1-B^{*}\right)\left(\pi_{i}^{N E}-\pi_{i}^{D}\right)+\pi_{i}^{D}-\pi_{i}^{C}}{B^{*} \pi_{i}^{D}-\pi_{i}^{C}+\left(1-B^{*}\right) \pi_{i}^{N E}}
$$

Ruling out breakdowns in collusion $\left(B^{*}=0\right)$ and assuming grim Nash reversion punishment strategies $\left(T_{i}=\infty\right)$ in (10), gives the standard critical discount factor for collusion ${ }^{24}: \delta \geq\left(\pi_{i}^{D}-\pi_{i}^{C}\right) /\left(\pi_{i}^{D}-\pi_{i}^{N E}\right)$. In addition, substituting in for the appropriate profit expressions (with constant demand equal to $M$ ) gives the critical discount factors derived in the Compte et al.

\footnotetext{
${ }^{23}$ See for example Ivaldi et al. (2003a).

${ }^{24}$ See for example Church and Ware (2000) pp. 331-4.
} 
(2002) model (as given in Table 1).

Returning to the general setting in (10) and noting that $\log (\delta)<0$ :

Proposition 4. Firm $i$ will not have an incentive to deviate from collusive behaviour as long as:

$$
T_{i}+1 \geq \log \left(\frac{\delta\left(1-B^{*}\right)\left(\pi_{i}^{N E}-\pi_{i}^{D}\right)+\pi_{i}^{D}-\pi_{i}^{C}}{B^{*} \pi_{i}^{D}-\pi_{i}^{C}+\left(1-B^{*}\right) \pi_{i}^{N E}}\right) / \log (\delta)
$$

For collusion to be sustainable the condition given in Proposition 4 must hold for all firms. The level of $T_{i}$ that ensures this is the case will be denoted $T^{*}$. As shown in Appendix B.3, collusion is sustainable with sufficiently long punishment periods if the probability of a breakdown is sufficiently low. More precisely:

Lemma 6. For collusive behaviour to be sustainable $B^{*}<B_{i}^{\max } \forall i$, where:

$$
B_{i}^{\max }=\frac{\pi_{i}^{C}-\pi_{i}^{D}+\delta\left(\pi_{i}^{D}-\pi_{i}^{N E}\right)}{\delta\left(\pi_{i}^{D}-\pi_{i}^{N E}\right)}
$$

Therefore as long as firms are sufficiently patient $(\delta \rightarrow 1)$ collusion is sustainable if for all $i$ :

$$
B^{*}<\frac{\left(\pi_{i}^{C}-\pi_{i}^{N E}\right)}{\left(\pi_{i}^{D}-\pi_{i}^{N E}\right)}
$$

$\underline{\text { Profits }}$

It is then possible to substitute in to the expression in Proposition 4 for $\pi_{i}^{C}, \pi_{i}^{D}$ and $\pi_{i}^{N E}$ as functions of the capacity and demand parameters:

- Collusive profits $\left(\pi_{i}^{C}\right)$ : it is optimal ${ }^{25}$ to set a collusive price $p_{i}=1 \forall i$ resulting in $\pi_{i}^{C}=\left(k_{i} / K\right) \tilde{M}$ (since from Lemma $3 K>M+u$ ) and therefore in expectation:

$$
\pi_{i}^{C}=\left(k_{i} / K\right) M
$$

- Punishment phase profits $\left(\pi_{i}^{N E}\right)$ : the static Nash equilibrium profits de-

\footnotetext{
${ }^{25}$ A lower collusive price leaves the relative gains from deviating unchanged but increases the static NE punishment profits relative to the foregone collusive profits. Collusive behaviour is therefore harder to sustain.
} 
pend upon the specific capacity distribution (see Lemma 1 and Proposition 1).

- Deviation profits $\left(\pi_{i}^{D}\right)$ : If firm $i$ deviates from collusive behaviour it optimally sets $p_{i}=1-\epsilon(\epsilon>0$ but small $)$ whilst $p_{j}=1 \forall j \neq i$. Therefore firm $i$ makes profit of approximately:

$$
\min \left\{k_{i}, \tilde{M}\right\}
$$

Where $k_{i}=\min \left\{k_{i}, M+u\right\}$. This is equal to $S_{i}^{L}$ as given by (1).

\subsection{Probability of collusion}

From section 4.2, collusive behaviour breaks down if industry demand is sufficiently low (denote sufficiently low demand as $\tilde{M} \leq \underline{M}$ where $\underline{M}$ is implicitly defined by Propositions $2 \& 3$ ) and this occurs with probability $B^{*}$. We can therefore distinguish between two possible demand levels each period: 'high' if $\tilde{M}>\underline{M}$ and 'low' when $\tilde{M} \leq \underline{M}$. If collusion breaks down a punishment period of length $T^{*}$ (as specified by Proposition 4) is then required. It is then possible to derive the probability (denoted $C_{t}$ ) that a given period of the game (period $t$ ) will be collusive, where $C_{t}$ is a function of $B^{*}$ and $T^{*}$. Whilst the detailed derivation of $C_{t}$ is confined to Appendix C, the intuition is relatively straightforward. Firstly, period $t$ will be collusive as long as the following condition is not satisfied:

Lemma 7. A necessary condition for period t to be a punishment period is that one of the previous $T^{*}$ periods must have had demand sufficiently low to trigger a punishment phase.

Proof: see Appendix C.1

To see the intuition behind Lemma 7, assume the most recent period with low demand was $T^{*}+1$ periods ago. This could potentially have triggered the start of a punishment phase (rather than being part of an ongoing punishment phase). However, sufficient time has still passed for collusion to have resumed and continued due to the recent run of high demand. 
Despite the necessary condition in Lemma 7, there are a number of circumstances under which period $t$ will still be collusive. To illustrate this, consider punishment phases lasting two periods $\left(T^{*}=2\right)$. From Lemma 7 a necessary condition for $t$ to be a punishment period is that at least one of the previous two periods must have had low demand. However, even if this was the case:

i. a punishment phase may have been triggered in $t-3$. This lasts for two periods after which collusion resumes in period $t$. Or;

ii. a punishment phase may have been triggered in period $t-4$ with collusion then resuming in $t-1$. This resumption would occur regardless of low demand in $t-2$. If, $t-1$ then has high demand, period $t$ will then also be collusive (despite potentially low demand in $t-2$ satisfying the necessary condition in Lemma 7).

As shown in Appendix C.2, the necessary condition in Lemma 7 and a series of additional qualifications like those described above, can be used to derive:

Proposition 5. The probability that period $t$ is collusive is given by:

$$
C_{t}=\left(1-B^{*}\right)^{T^{*}} /\left(\left(1-B^{*}\right)+T^{*} B^{*}\left(1-B^{*}\right)^{T^{*}}-B^{*} \sum_{i=1}^{T^{*}-1}\left(1-B^{*}\right)^{i}\right)
$$

Proof: see Appendix C.2

From which it follows that $\partial C_{t} / \partial B^{*}<0$ and $\partial C_{t} / \partial T^{*}<0$. As would be expected, a given period is more likely to be collusive if the punishment phase is short and breakdowns are unlikely to occur.

\section{Application to the Nestle/Perrier merger}

In this section the model will be used to compare the potential Nestle/Perrier merger outcomes. First, we outline the general approach taken, then analyse the case, initially considering the unilateral effect of the merger then the potential for collusive behaviour. 


\section{$5.1 \quad$ Approach}

Firstly, the expected market demand $(M)$ and the firms' common discount factor $(\delta)$ are set at appropriate levels. It is then possible, for a given capacity distribution and extent of demand fluctuations, using Propositions 2, 3 and 4 to solve for the probability that collusion will breakdown $\left(B^{*}\right)$ and the length of punishment phase necessary to sustain collusion $\left(T^{*}\right)$. Proposition 5 can then be used to find the probability that a given period is collusive $\left(C_{t}\right)$. During collusive periods price is set at the consumers' reservation price, resulting in zero consumer surplus. In contrast, punishment periods involve a switch to the static Nash equilibrium resulting in $C S_{N E}$ (see section 3). Therefore the overall expected consumer welfare is:

$$
C_{t}(0)+\left(1-C_{t}\right)\left(C S_{N E}\right)
$$

We can identify three distinct possibilities for the expected consumer welfare according to the likelihood of collusive behaviour:

- Full collusion: from Lemma 4 we know that the probability of breakdown $\left(B^{*}\right)$ is increasing in the size of demand fluctuations and equal to zero if demand fluctuations are sufficiently small. Assuming firms are sufficiently patient, if $B^{*}=0$ the probability of collusion in a given period is 1 and therefore $C S=0$. The level of $u$ below which $B^{*}=0$ will be denoted $\underline{u}$. Therefore for $u<\underline{u}$ collusion will be referred to as 'full' i.e. not subject to breakdowns.

- No collusion: from Lemma 6 we know that collusion is only sustainable if $B^{*}$ is not too high $\left(B^{*}<B_{i}^{\max } \forall i\right)$. The level of $u$ above which collusion is unsustainable will be denoted $\bar{u}$. Consequently, for $u>\bar{u}$ $C_{t}=0$ and unilateral behaviour takes place resulting in $C S=C S_{N E}$.

- Partial collusion: for $\underline{u}<u \leq \bar{u}$ collusion is subject to breakdowns $\left(B^{*}>0\right)$ but breakdowns are not sufficiently frequent to make collusion entirely unsustainable. Periods of both collusive and punishment behaviour occur $\left(0<C_{t}<1\right)$ with only the latter resulting in positive consumer welfare. 
It will then be possible to make welfare comparisons between two alternative scenarios involving either partial or no collusive behaviour. It is not necessarily the case that the scenario with no collusion will result in higher consumer welfare. It may be that the partially collusive outcome has a more competitive static Nash equilibrium and thus higher consumer welfare apart from during collusive periods. Consequently, if collusion breaks down sufficiently frequently, overall consumer welfare may in fact also be higher. Furthermore, since the more competitive static Nash equilibrium results in harsher punishments this actually helps to facilitate the collusive behaviour.

\section{$5.2 \quad$ Nestle/Perrier merger}

Following Compte et al. (2002), we set the expected market demand $(M)$ at 5250 million litres. The common firm discount rate $(\delta)$ is initially set at 0.9. Appendix D shows the effect of varying this assumption with the main differences discussed at the end of this section. Firstly, the impact of the merger absent remedies will be analyzed (i.e. Pre to Post). Then, the initial remedy offered by the parties (Remedy 1 ) and the eventual accepted remedy (Remedy 2) will also be considered (see section 1).

\section{Unilateral effect pre- to post-merger}

The conditions under which Proposition 1 holds are such that we can solve for the pre-merger static Nash equilibrium profits (and therefore consumer welfare) for demand fluctuations ${ }^{26}$ such that $u \leq 1650$. Therefore, within this range, comparing the pre- and post-merger consumer surplus under unilateral behaviour leads to ${ }^{27}$ :

Finding 1. For $u \leq 1650$ and assuming unilateral behaviour, the consumer surplus pre-merger $\left(C S_{P R E}=2496\right)$ exceeds the post-merger level $\left(C S_{P O S T}=\right.$ $617)$.

\footnotetext{
${ }^{26}$ Demand fluctuations above this level mean that the $n-1$ smaller firms are able to supply the entire demand for some realisations $\left(K_{-n} \geq M-u\right)$ and therefore the mixed strategy NE is undefined (see Proposition 1).

${ }^{27}$ In both cases $C S$ is constant over this range of demand fluctuations because of the specific capacity distributions.
} 
This first finding confirms, now with demand uncertainty, the evidence from the analysis in the introduction, that as a result of the merger absent any remedy a substantial unilateral effect can be expected. A move from the pre- to the post-merger capacity distributions increases the minimum price charged in the mixed strategy equilibrium $\left(p_{n}^{\min }\right)$ from 0.31 to 0.66 . Next, we consider the possibility of collusive behaviour, initially for the same two outcomes and range of demand fluctuations.

\section{Collusive behaviour pre- and post-merger}

In order to consider collusive behaviour we can now adopt the approach described in section 5.1 and solve for the range of demand fluctuations for which partial collusion occurs. Firstly, Figure 1 outlines the possibility of collusive behaviour pre-merger. Here, full collusion is sustainable up to $\underline{u}=$ 433 and then partial collusion until $\bar{u}=589$.

Figure 1: Collusive behaviour pre-merger

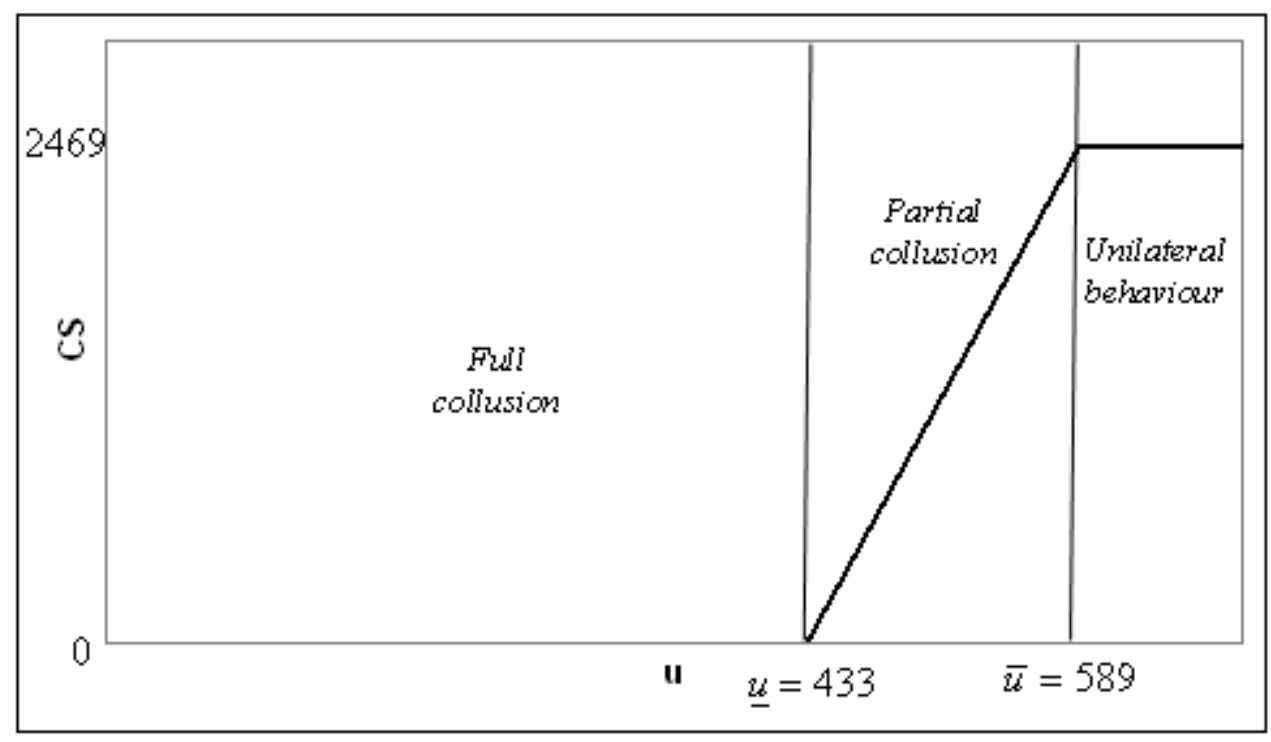


Once $u$ exceeds $\underline{u}$ subsequent increases in the size of the demand fluctuations increase the probability that collusion breaks down (Figure 2a). This increased likelihood of breakdown increases the gains from deviation relative to future collusive profits and therefore means that longer punishment phases are required to prevent deviations (Figure $2 \mathrm{~b}$ ). This in turn reduces the probability that a given period is collusive (Figure 2c) and increases expected consumer welfare. Absent collusive behaviour consumer surplus premerger equals 2469 (Finding 1), and therefore consumer surplus approaches this level. 
Figure 2: Key parameters

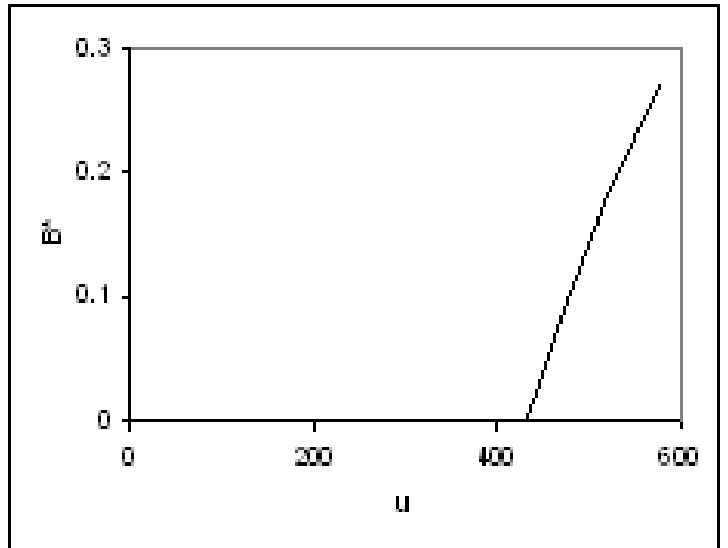

(a) $B^{*}$

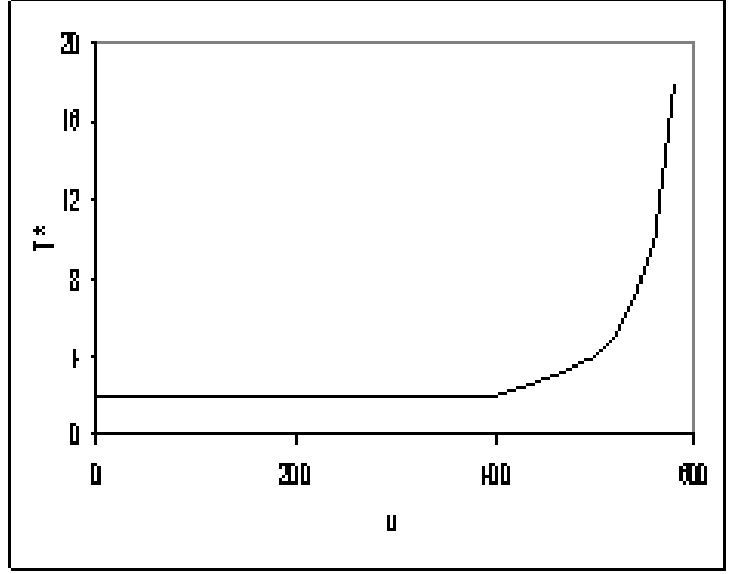

(b) $T^{*}$

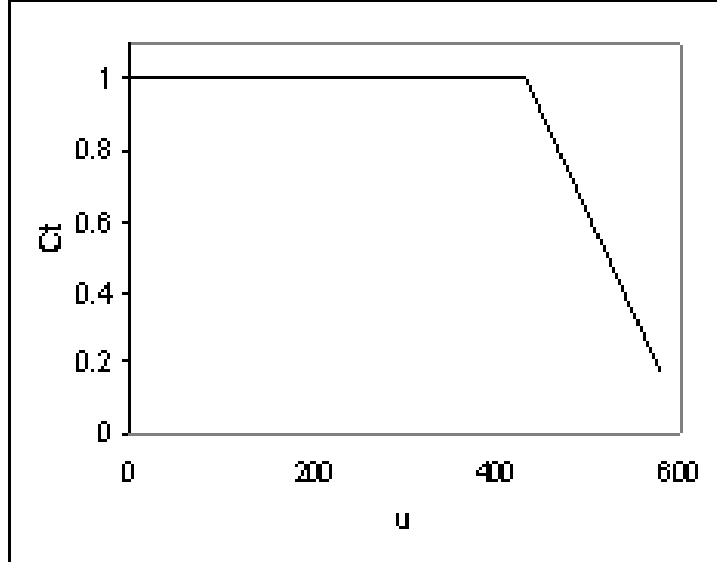

(c) $C_{t}$ 
Secondly, similar calculations for the post-merger scenario (absent remedies) show that not only would full collusion be sustainable for a reduced range of demand fluctuations (up to $\underline{u}=293$ ) but also partial collusion is only possible for a very limited range $(\bar{u}=313)$. Figure 3 then compares the predicted pre-merger consumer welfare (Figure 1) with that post-merger absent any remedies.

Figure 3: Comparing consumer welfare pre- and post-merger

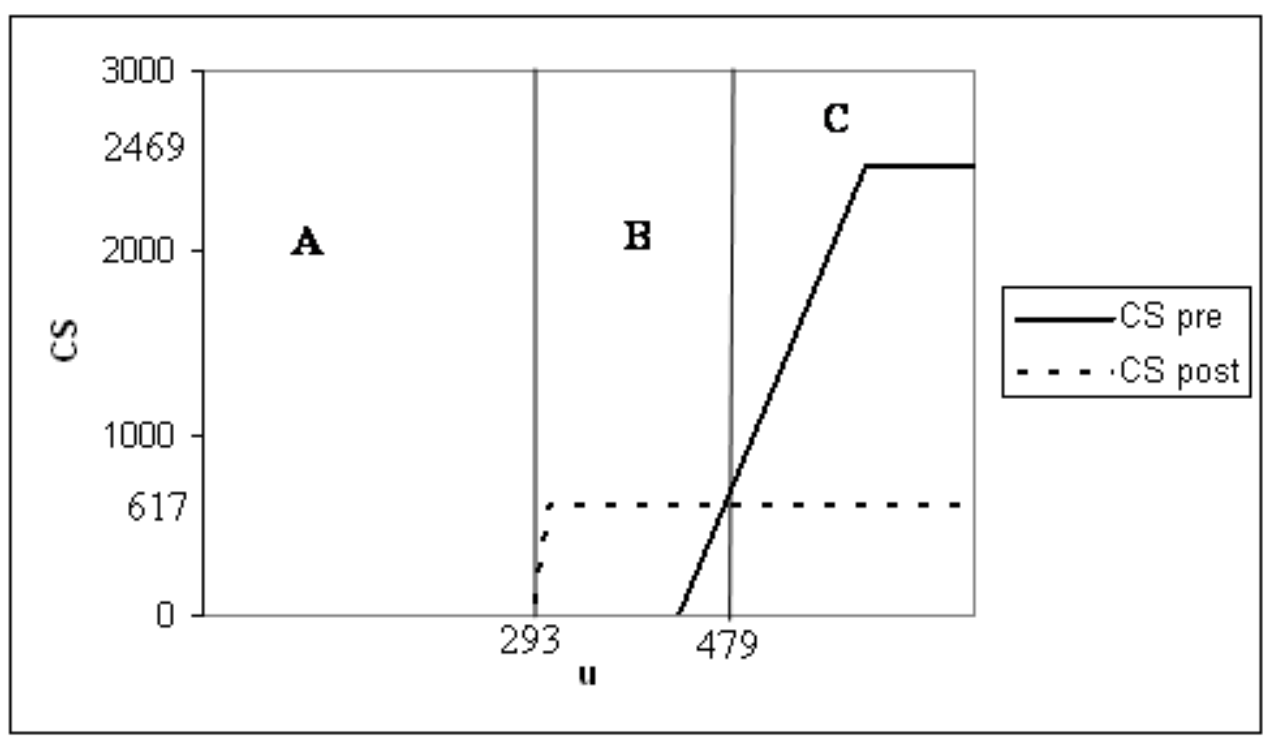

Figure 3 reveals three distinct regions:
A. $C S_{P R E}=C S_{P O S T}=0$ since in both cases full collusion is possible
B. $C S_{P R E}<C S_{P O S T}$ since full collusion is possible pre- but not post- merger
C. $C S_{P R E}>C S_{P O S T}$

Leading to the following finding: 
Finding 2. For $u>479$ predicted pre-merger consumer welfare is higher than from unilateral behaviour post-merger, despite the possibility of partial collusion pre-merger.

A level of demand fluctuations such that $u=479$ corresponds to demand fluctuations up to $9 \%$ from the expected demand. Below this will be compared to the equivalent range following the alternative remedies and to the available evidence on the extent of actual demand fluctuations.

\section{Collusive behaviour following Remedy 1 and 2}

So far comparisons have been made between the pre- and post-merger outcomes, we can now also consider the impact on collusive behaviour of the two remedies. Figure 4 reproduces Figure 1 for the capacity distributions resulting from Remedy 1 and 2.

Figure 4: Collusive behaviour Remedy $1 \& 2$

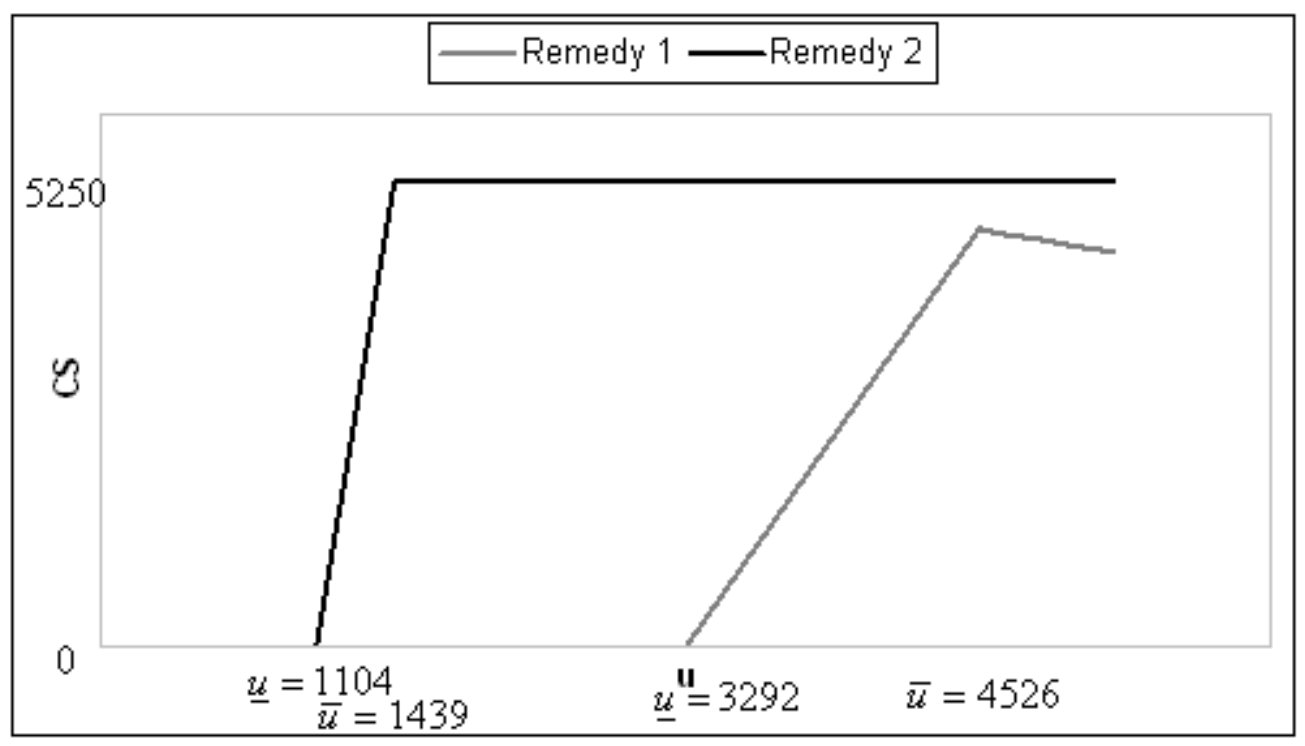

Here we can see a significant increase in the scope for collusive behaviour, in particular as a result of Remedy 1 but also from Remedy 2. Full collusion is now feasible for a much larger range of demand fluctuations, up to $\underline{u}=1104$ under Remedy 2 and even further to $\underline{u}=3292$ following Remedy 1 . In 
addition, the scope for partial collusion is enhanced, especially before the second remedy is imposed. Following Remedy 2, for $u \leq 4550$ the static Nash equilibrium results in marginal cost pricing (i.e. $p=0$ ) and therefore the maximum possible expected consumer surplus $(C S=5250)$. Therefore, as partial collusion becomes less sustainable the resulting consumer surplus under Remedy 2 approaches this level ${ }^{28}$.

\section{Comparing the unilateral effect pre- to post-merger with collusive behaviour post-remedy}

As earlier, it is also possible to make comparisons with the post-merger outcome before the imposition of remedies ${ }^{29}$.

Figure 5: Comparing the post-merger outcome with Remedy $1 \& 2$

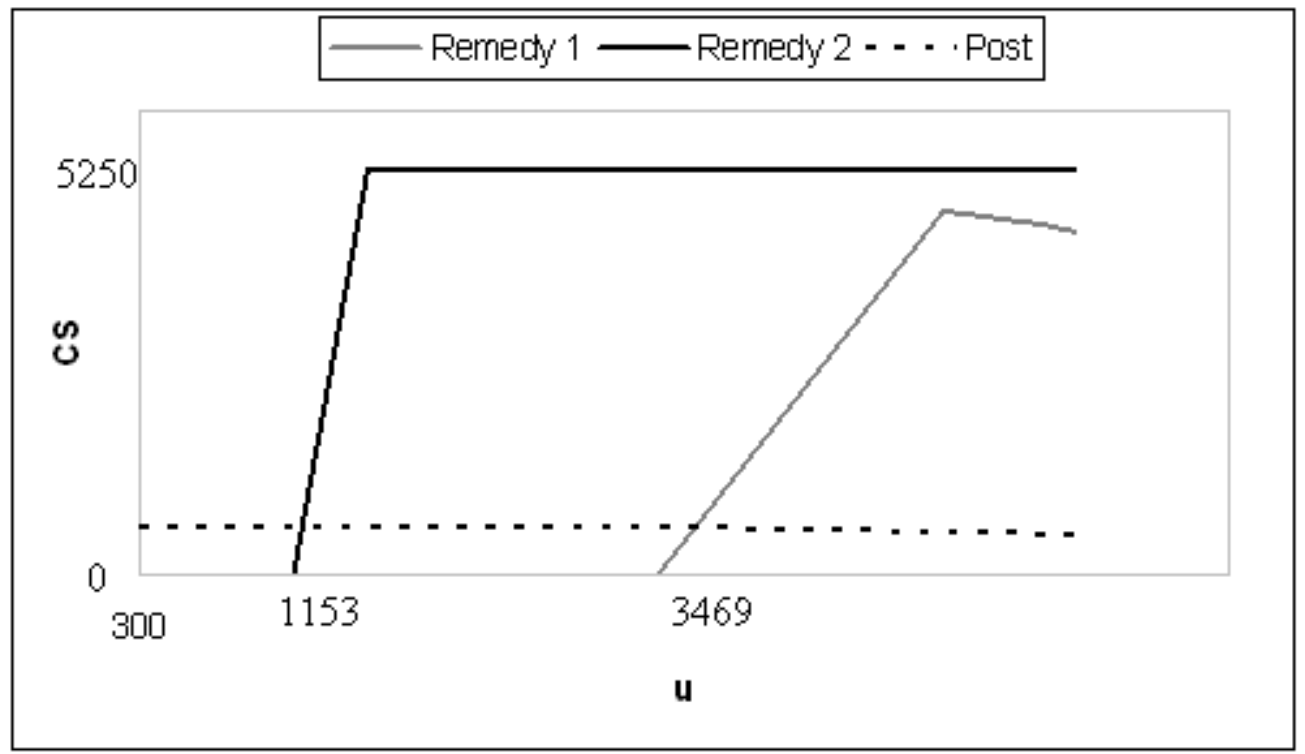

Figure 5 shows the critical size of demand fluctuations above which consumer surplus exceeds the level expected to result post-merger:

\footnotetext{
${ }^{28}$ For Remedy 1 the static Nash equilibrium $C S$ depends upon the size of demand fluctuations $(u)$. As Figure 4 shows, if demand fluctuations are sufficiently high that no collusive behaviour occurs, $C S$ then declines with subsequent increases in $u$.

${ }^{29}$ Below $u=293$, full collusion is possible under all three outcomes.
} 
Finding 3. Despite the possibility of partial collusion:

- for $u>1153$ predicted consumer welfare resulting from Remedy 2 is higher than from unilateral behaviour post-merger.

- for $u>3469$ predicted consumer welfare resulting from Remedy 1 is higher than from unilateral behaviour post-merger.

Finding 3 therefore shows that, even with partial collusion, it is possible that the remedies result in higher consumer surplus than expected beforehand. This is due to the substantial unilateral effect predicted post-merger (see Finding 1) and is much more likely as a result of Remedy 2 where possible demand fluctuations $22 \%$ from the expected demand are required, compared to $66 \%$ following Remedy 1 .

Evidence provided in the EC merger decision suggests that demand fluctuations do occur in this market. For example, exceptionally high demand growth of $8.5 \%$ in 1990 was followed by growth of only $0.9 \%$ the following year. Furthermore, these fluctuations would seem to be unpredictable with weather conditions being an important determinant ${ }^{30}$. It is then important to consider the impact this has on market transparency. The evidence uncovered by the European Commission suggests that pre-merger transparency may have been high, especially because of list prices published by the main players in the industry ${ }^{31}$. However, rebates offered to suppliers may still result in some reduction in transparency. In addition, this suggests that absent this information a lack of transparency may represent an important impediment to coordination. Importantly, therefore, as part of the accepted remedies package the European Commission imposed conditions prohibitinh such information disclosure ${ }^{32}$. This demonstrates an important role for policy in creating the conditions that make breakdowns in tacitly collusive behaviour more likely.

Despite Finding 3, the eventual accepted remedies (Remedy 2) may still be criticised for enhancing the possibility of collusion compared to the premerger outcome (contrast Figures $1 \& 4$ ). However, as Compte et al. discuss,

\footnotetext{
${ }^{30}$ M.190 Nestle/Perrier (1992), para 68.

${ }^{31}$ M.190 Nestle/Perrier (1992), para 62.

${ }^{32}$ M.190 Nestle/Perrier (1992), para 136.
} 
an outright prohibition of the merger may have been difficult. This was the first application of the EC Merger Regulation to collective dominance and an appeal by the merging parties would have be likely. Under this constraint, the above analysis confirms the importance of the second remedy in reducing the sustainability of tacitly collusive behaviour.

All the results in section 5 have assumed that firms have a relatively high discount rate $(\delta)$ of 0.9 . Appendix $\mathrm{D}$ shows the effect of varying this assumption. The most significant effect of a lower $\delta$ is a reduction in the range of demand realisations for which partial collusion is possible. In addition, a lower $\delta$ can (due to an increase in $T^{*}$ ) also lead to a small increase in the consumer surplus resulting from partial collusion. Assuming a high value for $\delta$ therefore provides a lower bound on the predicted consumer welfare.

\section{Conclusion}

This paper has shown that the remedies imposed by the European Commission in the Nestle/Perrier case can be seen in a more favourable light. We show that, despite leading to an outcome less conducive to collusion, the merger absent remedies would be likely to harm consumer welfare due to a substantial unilateral effect. Even though the remedies may have made collusion more likely, collusive behaviour might breakdown and result in sufficiently frequent/long price wars to improve consumer welfare compared to the un-remedied merger.

This consumer welfare trade-off between outcomes has been demonstrated in a setting which is specific in two respects. Firstly, the case examined highlights the conflict between theories of harm particularly starkly because of the increased number of possible outcomes due to the rejected early remedy offer by the parties. Secondly, the specific model of Compte et al. (2002), a model tailored to fit the features of the Nestle/Perrier case, has been extended. However, as discussed in the introduction, this case is illustrative of a far more general theoretical trade-off between unilateral and coordinated effects. In addition, as Davies and Olczak (2008) have demonstrated within a sample of EC merger decisions this trade-off has important policy implica- 
tions. Furthermore, this trade-off could potentially be assessed using a range of models which allow for breakdowns in collusive behaviour.

The approach taken in this paper to assessing merger outcomes is also related to the merger simulation literature. Whilst simulation is now reasonably well established for examining unilateral effects a recently emerging literature (Davis (2006), Sabbatini (2006) and Hikisch (2008)) aims to extend it to the context of coordinated effects analysis. The approach taken in these papers has been, much like here, to construct a model of collusive behaviour and consider how the likelihood of collusion behaviour varies under alternative market structures. However, these previous studies have adopted models with no demand uncertainty and simulated the impact of a merger on the critical discount factor required for collusive behaviour. In contrast, in our approach comparisons between outcomes will also depend upon the level of transparency, captured in this specific model by the level of demand uncertainty. Importantly, our approach allows comparisons between outcomes where different theories of harm (i.e. unilateral or collusive behaviour) are expected. Arguably, in many cases evidence on the degree of transparency and extent of demand fluctuations is more quantifiable than attempting to measure the rate at which firms discount the future.

The analysis of the Nestle/Perrier case has illustrated the effect increased firm numbers and asymmetries can have on destabilising tacit collusion. The additional remedy insisted upon by the European Commission has been shown to reduce the effectiveness of collusion. Here, the presence of an additional, smaller player reduces transparency and makes breakdowns in collusion more likely. This is in contrast to the Compte et al. model where only asymmetries and not directly firm numbers affect the sustainability of collusion $^{33}$. This suggests a potential extension to the model. In all of the cases considered here, it has been assumed that all of the main players in the industry form the potentially tacitly collusive group. However, since the smaller firm potentially destabilises collusion, it might be in the two larger

\footnotetext{
${ }^{33}$ In their model the critical discount factor depends only on the relative size of the largest firm compared to total capacity because of the effect this has on punishment profits.
} 
firms' interests to allow the smaller firms to free-ride on their tacitly collusive behaviour and only punish potential deviations by each other. Despite reducing their own sales, our analysis suggests a potential advantage would be less frequent breakdowns in collusive behaviour. A second issue, not so far allowed for in the model, is potential coordination failure i.e. one firm commencing punishment behaviour whilst other rival(s) continue to collude for at least one additional period. This would appear to make collusive behaviour harder to sustain. In a similar fashion, alternative assumptions regarding the cause of a breakdown in collusion could also be considered.

\section{A Static Nash equilibrium}

Here, to minimise on notation, $S_{i}$ will be denoted as $S_{i}\left(p_{i}, p_{-i}\right)$ where $p_{-i}$ refers to the vector of prices set by firm $i^{\prime} s n-1$ rivals.

\section{A.1 Proof of Lemma 1 - Existence of a pure strategy Nash equilibrium}

First, it will be useful to establish three important properties of the mixed strategy NE. Consider a mixed strategy NE in which firm $i$ chooses prices randomly over the interval $\left[\underline{p}_{i}, \bar{p}_{i}\right]$ :

- Property 1: For this to be a mixed strategy NE the expected profit $\left(\pi_{i}\right)$ of firm $i$ must be constant $\forall p: \underline{p}_{i} \leq p_{i} \leq \bar{p}_{i}$. In particular, expected profit must be the same at both the upper and lower support of firm $i$ 's pricing distribution i.e. $\underline{p}_{i}$ and $\bar{p}_{i}$.

- Property 2a: Denote: $\bar{p}^{\max } \equiv \max \left\{\bar{p}_{i}\right\}$. When firm $i$ sets $p_{i}=\bar{p}^{\max }$ it must the highest price firm in the market with probability 1 . A positive probability of a tie at this price would require more than one firm to have probability mass at this price. However, all but one of these firms can definitely increase their sales ${ }^{34}$ and therefore profit by reducing its

\footnotetext{
${ }^{34} K>M-u$ ensures that this is true in expectation.
} 
mass point to $\bar{p}^{\max }-\epsilon(\epsilon>0$ but small $)$, thus removing the probability of a tie at this price.

- Property 2b: Denote: $\underline{p}^{\text {min }} \equiv \min \left\{\underline{p}_{i}\right\}$ and $\underline{p}_{j}=\underline{p}^{\text {min }} \forall j$. When firm $j$ sets $p_{j}=\underline{p}^{\text {min }}$ it must either be the lowest price firm in the market with probability 1 or $\sum_{j} k_{j} \leq M-u$. This is because as long as $\sum_{j} k_{j}>M-u$ if there is a positive probability of a tie at $\underline{p}^{\text {min }}$ then in expectation it is profitable for firm $j$ to reduce its price to $\underline{p}^{\text {min }}-\epsilon$ $(\epsilon>0$ but small).

- Property 3: $\bar{p}^{\max }=1$. To see this, consider $\bar{p}^{\max }<1$, if firm $i$ sets $p_{i}=\bar{p}^{\max }$ from Property 2a) it is the highest priced firm in the market with probability 1 . From section 2.2 it therefore sells $S_{i}^{H}=$ $\max \left\{\tilde{M}-K_{-i}, 0\right\}$. As long as $M+u>K_{-n}$ (a requirement for a mixed strategy NE established in Lemma 1) $S_{n}^{H}>0$ with positive probability. More generally $S_{i}^{H}>0$ for a firm $i$ with capacity such that $M+u>K_{-i}$. It is therefore profitable for any such firm to increase $\bar{p}^{\max }$ to 1 .

Lemma 1 considers potential pure strategy NE, first in can be shown that in any such equilibrium all firms set an identical price i.e. $p_{i}=p \forall i$. To see this, consider an alternative equilibrium in which firms set prices such that: $p_{i}=p_{X} \forall i \in X, p_{j}=p_{Y} \forall j \in Y$ where $p_{X}<p_{Y} \leq 1$, and $p_{k}>p_{Y} \forall k \notin$ $X, Y$. It follows from the demand rationing scheme described in section 2.2 that:

- $S_{j}>0 \forall j \in Y$ iff $S_{i}=k_{i} \forall i \in X$. In which case firm $i$ has an incentive to increase its price to $p_{i}=p_{Y}-\epsilon$ (for $\left.\epsilon>0\right)$. Otherwise;

- $S_{j}=0 \forall j \in Y$. In which case, by setting the lowest price $S_{j}>0$ and firm $i$ therefore has an incentive to reduce its price to $p_{X}$ (or is indifferent if $\left.p_{X}=0\right)$.

It is now possible to prove the existence of pure strategy NE for the two cases stated in Lemma 1: 
a. If $K \leq M-\boldsymbol{u}$. The only equilibrium of the game involves pricing at the consumers' reservation price $\left(p_{i}=1 \forall i\right)$ with firms selling their entire capacity $\left(\pi_{i}^{N E}=k_{i} \forall i\right)$.

Here, $\forall p_{i}: 0 \leq p_{i} \leq 1 S_{i}\left(p_{i}, p_{-i}\right)=k_{i} \forall \tilde{M}$. Consequently $p_{i}=1=p_{\text {mon }}$ can be sustained as the unique pure strategy $\mathrm{NE}$, resulting in $\pi_{i}^{N E}=$ $k_{i} \forall i$.

In addition, there is no mixed strategy NE. To see this first note that from Property 3 in a mixed strategy NE $\bar{p}_{i}=1$ for at least one firm. Secondly, $S_{i}\left(p_{i}, p_{-i}\right)=k_{i}$ and therefore $\pi_{i}$ falls $\forall p<1$. However, from Property 1 the expected profit must be the same at all prices in a firms support.

b. If $K_{-n} \geq M+u$. The only equilibrium of the game involves marginal cost pricing $\left(p_{i}=0 \forall i\right)$ and therefore $\pi_{i}^{N E}=0 \forall i$ Here, $K_{-n} \geq \tilde{M} \forall \tilde{M}$ and as firm $n$ is the largest firm $K_{-i} \geq \tilde{M} \forall \tilde{M}$. In other words any subgroup of $n-1$ firms can, together, supply the entire market demand for any $\tilde{M}$. Therefore, $p_{i}=0$ and $\pi_{i}^{N E}=0 \forall i$ is a pure strategy NE since $S_{i}\left(p_{i}, 0\right)=0 \forall p_{i}>0$.

To see that $p_{i}=0 \forall i$ is a unique NE pure strategy NE consider an alternative with $p=\hat{p} \forall i$ where $0<\hat{p} \leq 1$. Here, $S_{i}(\hat{p}, \hat{p})=$ $\min \left\{k_{i},\left(k_{i} / k\right) \tilde{M}\right\}=\left(k_{i} / K\right) \tilde{M}$ as $K>\tilde{M} \forall \tilde{M}$. It then follows that firm $i$ can profitably undercut $\hat{p}$ as $S_{i}(\hat{p}-\epsilon, \hat{p})=\min \left\{k_{i}, \tilde{M}\right\}>S_{i}(\hat{p}, \hat{p}) \forall \tilde{M}$ (for $\epsilon>0$ ).

In addition, here there is no mixed strategy NE. From Property 3 at least one firm must set $p_{i}=1$ with positive probability. From Property 2a) at this price it will be the highest priced firm in the market with probability 1 and make $\pi_{i}=0$. Consequently, from Property 1 this firm must also set $p_{i}=0$ with positive probability, again resulting in $\pi_{i}=0$. However, contrary to Property 1, for some price within the support such a firm will obtain a positive profit with some probability and this therefore rules out the existence of a mixed strategy NE. 
In contrast, For $K>M-u$ and $K_{-n}<M+u$ there is no equilibrium in pure strategies

First we can show that any potential pure strategy NE with $p_{i}=\hat{p} \forall i$ where $0<\hat{p} \leq 1$ is susceptible to a profitable downward deviation. $S_{i}(\hat{p}, \hat{p})=$ $\min \left\{k_{i},\left(k_{i} / K\right) \tilde{M}\right\}$ and $S_{i}(\hat{p}-\epsilon, \hat{p})=\min \left\{k_{i}, \tilde{M}\right\}$ (for $\epsilon>0$ ). Therefore for $\epsilon>0$ but small, either:

- $S_{i}(\hat{p}-\epsilon, \hat{p})=S_{i}(\hat{p}, \hat{p})$ if $k_{i}<\left(k_{i} / K\right) \tilde{M}$ i.e. $K<\tilde{M}$ or;

- $S_{i}(\hat{p}-\epsilon, \hat{p})>S_{i}(\hat{p}, \hat{p})$ if $K>\tilde{M}$.

Since $K>M-u$ the latter occurs with positive probability and therefore a downward deviation is profitable. Secondly, we can show that a potential pure strategy NE with $p_{i}=0$ and consequently $\pi_{i}=0 \forall i$ is susceptible to a profitable upward deviation. For the largest firm deviating to $p_{n}$, where $0<p_{n} \leq 1$, results in $S_{n}\left(p_{n}, 0\right)=\min \left\{\max \left\{\left(\tilde{M}-K_{-n}\right), 0\right\}, k_{n}\right\}$. Since $K_{-n}<M+u$ this is positive with positive probability and therefore such a deviation results in positive expected profits (more generally this will apply for any firm for which $K_{-i}<M+u$ ).

\section{A.2 Proof of Proposition 1 - mixed strategy Nash equi- librium profits}

Whilst a full characterisation of the mixed strategy NE is not required, the resulting expected profits are needed so that the consumer welfare can be derived. A first step in solving for the equilibrium profits is to consider the minimum price each of the firms is prepared to set in order to become the lowest price seller. From section 2.2:

i. if $p_{i}<p_{-i}$ firm $i$ makes sales of $S_{i}^{L}$.

ii. if $p_{i}>p_{-i}$ it is then clearly most profitable for firm $i$ to charge a price equal to the consumers reservation price i.e. $p_{i}=1$, resulting in profit of $S_{i}^{H}$.

In i), by undercutting all other firms prices firm $i$ clearly gains sales. It is therefore possible to solve for the lowest price (denoted $p_{i}^{\text {min }}$ ) which leaves 
firm $i$ indifferent between these two alternatives:

$$
p_{i}^{\min }=\frac{S_{i}^{H}}{S_{i}^{L}}
$$

Holding $K$ constant, it can then be shown that $\partial p_{i}^{n} / \partial k_{i}>0$ for all possible levels of $S_{i}^{H}$ and $S_{i}^{L}$ (see (1) and (2) in section 2.2), i.e.:

$$
p_{n}^{\min } \geq p_{n-1}^{\min } \geq \ldots \geq p_{1}^{\min }
$$

Intuitively, a larger share of total capacity results in increased sales as both the highest and lowest price firm, however, crucially the latter effect dominates.

We can now consider the lowest price ever charged in equilibrium $\left(\underline{p}^{\text {min }}\right)$. It will be useful to refer to any firm other than the largest as firm $j$ i.e. $j<n$. Firstly, consider the duopoly case. Since the largest firm (firm 2) will never set a price below $p_{2}^{\text {min }}$, firm $\mathrm{j}$ is able to set $p_{j}=p_{2}^{\text {min }}-\epsilon(\epsilon>0)$ and make profit of:

$$
p_{2}^{\min } S_{1}^{L}
$$

Secondly, for $n>2$ and in the specific case where $K_{-n} \leq M-u$, by setting $p_{j}=p_{n}^{\text {min }}-\epsilon(\epsilon>0$ but small $)$ firm $j$ is guaranteed profit of ${ }^{35}$ :

$$
p_{n}^{\min } k_{j}=p_{n}^{\min } S_{j}^{L}
$$

Consequently, both (15) and (16) imply that in the mixed strategy NE firm $j$ must be guaranteed profits of at least:

$$
p_{n}^{\min } S_{j}^{L}
$$

This demonstrates that in equilibrium $\underline{p}^{\min } \geq p_{n}^{\text {min }}$. Next, it can be shown that in fact $\underline{p}_{j}=p_{n}^{\text {min }}$. To see this firstly consider $\underline{p}^{\text {min }}>p_{n}^{\text {min }}$. From Property 3 the highest price ever charged $\left(\bar{p}^{\max }\right)$ is equal to 1 and from Property 2a) the firm setting this price is the highest priced seller with

\footnotetext{
${ }^{35}$ Note that without the restriction that $K_{-n} \leq M-u$ firm $j$ is not guaranteed to sell to its full capacity at this price and therefore has an incentive to undercut further.
} 
probability 1. However, it follows from the definition of $p_{n}^{\text {min }}$ that any firm for which $\bar{p}_{i}=1$ would increase its profits by instead setting $p=p^{\text {min }}-\epsilon$ (for $\epsilon>0$ but small) with probability 1 . Therefore it is not possible for there to be a mixed strategy NE with $\underline{p}^{\text {min }}>p_{n}^{\text {min }}$.

Now, consider $\underline{p}_{i}=p_{n}^{\text {min }} \forall i$. From Property $2 \mathrm{~b}$ ) this guarantees firm $j$ profits as given by (17). Furthermore, firm $n$ will set ${ }^{36} \bar{p}_{n}=1$ and Property $2 \mathrm{a}$ ) and $2 \mathrm{~b}$ ) ensure that this results in the same profit as when setting $p_{n}=p_{n}^{\min }=\underline{p}^{\min }$ (i.e. Property 1 is satisfied). Consequently, at $\underline{p}_{i}=p_{n}^{\min }$ Property 2a) guarantees each firm has $p_{i}<p_{-i}$ resulting in profits of $p_{n}^{\min } S_{i}^{L}$. Therefore using (14) and Property 1:

Proposition 1. For $K>M-u$ and $K_{-n}<M+u$, if either: $n=2$, or $n>2$ and $K_{-n} \leq M-u$, there is a mixed strategy Nash equilibrium with expected profits given by $\pi_{i}^{N E}=\left(S_{n}^{H} / S_{n}^{L}\right) S_{i}^{L}$.

\section{A.3 Average prices in the static Nash equilibrium with no demand uncertainty (Table 1)}

When there is no demand uncertainty ${ }^{37}$, i.e. each period the realisation of demand is equal to $M$, it follows from Proposition 1 that a mixed strategy NE exists $^{38}$ if $K>M$ and $K_{-n}<M$. In this case $S_{i}^{L}=k_{i}$ and $S_{n}^{H}=M-K_{-n}$. Therefore from Proposition 1:

$$
\pi_{i}^{N E}=\left(M-K_{-n}\right) \frac{k_{i}}{k_{n}}
$$

Fonseca and Normann (2008, p.390) show that by using (18) the average quantity weighted prices can be derived. Denote $q_{i}$ as the quantity sold by

\footnotetext{
${ }^{36}$ It follows from the definition of $p_{i}^{\text {min }}$ that if $k_{j}<k_{n}$ firm $j^{\prime} s$ profits in (17) exceed its profits from setting $\bar{p}_{j}=1$ and being the highest priced seller in the market. Consequently, firm $j$ must randomise over $\left[p_{n}^{\text {min }}, 1\right)$ and firm $n$ has a mass point at $p_{n}=1$, thus satisfying Property 1.

${ }^{37}$ See Fonseca and Normann (2008) for a complete derivation of the mixed strategy NE in this case.

${ }^{38}$ In contrast to the case with demand uncertainty described above, here no restriction is required when $n>2$. There are 2 possibilities: either $K_{-n}<M$ and the smaller firms can sell their entire capacity by undercutting $p_{n}^{\text {min }}$, or $K_{-n} \geq M$ and marginal cost pricing results (as in Lemma $1 b$ ).
} 
firm $i$ and note that $\sum_{i=1}^{n} q_{i}=M$. The average quantity weighted price $\left(p^{N E}\right)$ is given by $\sum_{i=1}^{n} p_{i} q_{i} / \sum_{i=1}^{n} q_{i}$ which can be rewritten as $p^{N E}=\sum_{i=1}^{n} \pi_{i}^{N E} / M$. Therefore using (18):

$$
p^{N E}=\left(M-K_{-n}\right) \frac{K}{M k_{n}}
$$

Substituting in to (19) for the appropriate capacity levels ${ }^{39}$ from Table 1 gives the pre- and post-merger static NE average prices as in the final row of the table. In addition, the intuition for the pure strategy static NE with $p=0$ as a result of Remedy 1 and Remedy 2 follows from Lemma 1 (b).

\section{B Breakdown in collusion}

\section{B.1 Proof of Lemma 5}

From (5):

$$
B_{i}=\operatorname{Prob}\left(\tilde{M} \leq\left(M+u-k_{j}\right)\left(\frac{K}{K-k_{j}}\right)\right)
$$

Differentiating the right-hand side of $(20)$ with respect to $k_{j}$ gives:

$$
\partial f / \partial k_{j}=\frac{-K\left(K-k_{j}\right)+\left(M+u-k_{j}\right) K}{\left(K-k_{j}\right)^{2}}
$$

Simplifying (21) gives: $\partial f / \partial k_{j}=(M+u-K) /\left(K-k_{j}\right)^{2}$, which is negative since from Lemma $3 K>M+u$.

\section{B.2 Proof of Proposition 3}

From Proposition 2:

$$
\begin{aligned}
B_{1} & =\frac{\left(M+u-k_{2}\right)\left(K / K_{-2}\right)-(M-u)}{2 u} \\
B_{m} & =\frac{\left(M+u-k_{1}\right)\left(K / K_{-1}\right)-(M-u)}{2 u}
\end{aligned}
$$

\footnotetext{
${ }^{39}$ In addition, note that as explained in section $2.1 k_{i}=\min \left\{\hat{k}_{i}, M\right\}$ and from the discussion of Table $1 M=5250$.
} 
Where: $1<m \leq n$. Therefore $B_{m}>B_{1}$ iff:

$$
\left(M+u-k_{1}\right)\left(\frac{K}{K_{1}}\right)>\left(M+u-k_{2}\right)\left(\frac{K}{K_{2}}\right)
$$

Since $K_{-i}=K-k_{i}(22)$ can be rewritten as:

$$
\left(M+u-k_{1}\right)\left(K-k_{2}\right)>\left(M+u-k_{2}\right)\left(K-k_{1}\right)
$$

Multiplying out the brackets and rearranging (23) gives:

$$
\left(k_{2}-k_{1}\right) K>(M+u)\left(k_{2}-k_{1}\right)
$$

Which is true for $k_{2}>k_{1}$ since from Lemma $3 K>M+u$.

\section{B.3 Proof of Lemma 6}

From Proposition 4 collusion is sustainable iff:

$$
T_{i}+1 \geq \log \left(\frac{\delta\left(1-B^{*}\right)\left(\pi_{i}^{N E}-\pi_{i}^{D}\right)+\pi_{i}^{D}-\pi_{i}^{C}}{B^{*} \pi_{i}^{D}-\pi_{i}^{C}+\left(1-B^{*}\right) \pi_{i}^{N E}}\right) / \log (\delta)
$$

Since $\log (\delta)<0$, a value of $T_{i}$ satisfying (24) exists iff:

$$
\log \left(\frac{\delta\left(1-B^{*}\right)\left(\pi_{i}^{N E}-\pi_{i}^{D}\right)+\pi_{i}^{D}-\pi_{i}^{C}}{B^{*} \pi_{i}^{D}-\pi_{i}^{C}+\left(1-B^{*}\right) \pi_{i}^{N E}}\right)<0
$$

This is turn requires:

$$
0<\frac{\delta\left(1-B^{*}\right)\left(\pi_{i}^{N E}-\pi_{i}^{D}\right)+\pi_{i}^{D}-\pi_{i}^{C}}{B^{*} \pi_{i}^{D}-\pi_{i}^{C}+\left(1-B^{*}\right) \pi_{i}^{N E}}<1
$$

It can then be shown that since $\pi_{i}^{D}>\pi_{i}^{N E}$ :

$$
\delta\left(1-B^{*}\right)\left(\pi_{i}^{N E}-\pi_{i}^{D}\right)+\pi_{i}^{D}-\pi_{i}^{C}>B^{*} \pi_{i}^{D}-\pi_{i}^{C}+\left(1-B^{*}\right) \pi_{i}^{N E}
$$

Consequently, (25) is only satisfied if:

$$
\delta\left(1-B^{*}\right)\left(\pi_{i}^{D}-\pi_{i}^{N E}\right)+\pi_{i}^{D}-\pi_{i}^{C}<0
$$


Rearranging (26) gives $B_{i}^{\max }$ as defined in Lemma 6:

$$
B_{i}^{\max }=\frac{\pi_{i}^{C}-\pi_{i}^{D}+\delta\left(\pi_{i}^{D}-\pi_{i}^{N E}\right)}{\delta\left(\pi_{i}^{D}-\pi_{i}^{N E}\right)}
$$

\section{Probability of collusion}

\section{C.1 Proof of Lemma 7}

As explained in section 4.4 , it is possible to distinguish between two possible states of demand each period: high $(H)$ if $\tilde{M}>\underline{M}$ and low $(L)$ when $\tilde{M} \leq \underline{M}$. The realisation of demand in period $t\left(\tilde{M}_{t}\right)$ will be: $\tilde{M}_{t}=L$ with probability $B^{*}$ and $\tilde{M}_{t}=H$ with probability $1-B^{*}$. Breakdowns in collusive behaviour occur if demand is low and then a punishment period of length $T^{*}$ (as specified by Proposition 4) is required. After $T^{*}$ periods, collusion resumes in the subsequent period and continues as long as demand remains high. There are therefore two possible outcomes (denoted $x_{t}$ ) for any period of the game, it is either collusive $(C)$ or a punishment period $(P)$ i.e.: $\left\{x_{t}=j: j \in C, P\right\}$. In addition, the subscript $e$ will be used to denote the end period of a $T^{*}$ punishment phase. Therefore, $x_{t}=P_{e}$ implies that $x_{t+1}=C$. Lemma 7 provides a necessary condition for period $t$ to be a punishment period:

Lemma 7. A necessary condition for period t to be a punishment period is that one of the previous $T^{*}$ periods must have had demand sufficiently low to trigger a punishment phase.

In contrast, assume:

$$
\tilde{M}_{p}=H \forall p
$$

where $t-T^{*} \leq p \leq t-1$.

There are then three possibilities for period $t-\left(T^{*}+1\right)$ :

i. Ongoing collusion: $x_{t-\left(T^{*}+1\right)}=C$ and $\tilde{M}_{t-\left(T^{*}+1\right)}=H$. Therefore, $x_{t-T^{*}}=C$ and it follows from $(27)$ that $x_{p}=C \forall p$ where $t-T^{*}-1 \leq$ $p \leq t$ 
ii. Breakdown in period $t-\left(T^{*}+1\right): x_{t-\left(T^{*}+1\right)}=C$ and $\tilde{M}_{t-\left(T^{*}+1\right)}=L$. However, the $T^{*}$ period punishment phase ends in period $t-1\left(x_{t-1}=\right.$ $\left.P_{e}\right)$ and consequently $x_{t}=C$.

iii. Ongoing punishment phase: $x_{t-\left(T^{*}+1\right)}=P$. However, at most the punishment phase continues for another $T^{*}-1$ periods. In this case $x_{t-2}=P_{e}$ and therefore $x_{t-1}=C$. From $(27) \tilde{M}_{t-1}=H$ and therefore $x_{t}=C$. In other cases the ongoing punishment phase continues for a shorter number of periods, with collusion then resuming and continuing due to (27).

Consequently, i)-iii) show that (27) is a sufficient condition to ensure that period $t$ is a collusive period and Lemma 7 follows from this.

\section{C.2 Proof of Proposition 5}

From Lemma 7 a necessary condition for period $t$ to be a punishment period is that at least one of the previous $T^{*}$ periods had low demand. This occurs with probability:

$$
1-\left(1-B^{*}\right)^{T^{*}}
$$

However, since collusive behaviour resumes for at least one period following $T *$ punishment periods, there are several circumstances which will result in period $t$ being collusive $\left(x_{t}=C\right)$ despite the necessary condition in Lemma 7 being satisfied.

Despite one of the previous $T^{*}$ periods having had low demand $x_{t}=C$ if:

i. A $T^{*}$ period punishment phase ends in period $t-1$ i.e. $x_{t-2}=$ $P_{e}$. This requires $x_{t-\left(T^{*}+1\right)}=C$ and $\tilde{M}_{t-\left(T^{*}+1\right)}=L$ (i.e. period $t-(T *$ +1 ) was collusive but had low demand) which occurs with probability:

$$
C_{t-\left(T^{*}+1\right)} B^{*}
$$

where $C_{t-\left(T^{*}+1\right)}$ denotes the probability that period $t-\left(T^{*}+1\right)$ is collusive. 
ii. OR,

- a $T^{*}$ period punishment phase ends in period $t-2$ (and therefore given Lemma $\left.7 T^{*} \geq 2\right)$. This requires $x_{t-\left(T^{*}+2\right)}=C$ and $\tilde{M}_{t-\left(T^{*}+2\right)}=L$ which occurs with probability:

$$
C_{t-\left(T^{*}+2\right)} B^{*}
$$

- AND demand was high in period $t-1$. Bayes rule can be used to show that the probability $\tilde{M}_{t-1}=H$ given that the necessary condition in Lemma 7 requires that $\tilde{M}_{p}=L$ for some $t-T^{*} \leq p \leq t-1$ is:

$$
1-\left(\frac{B^{*}}{\left(1-\left(1-B^{*}\right)^{T^{*}}\right)}\right)
$$

Combining (30) and (31), ii) occurs with probability:

$$
\left(C_{t-\left(T^{*}+2\right)} B^{*}\right)\left(1-\left(\frac{B^{*}}{\left(1-\left(1-B^{*}\right)^{T^{*}}\right)}\right)\right)
$$

iii. OR,

- a $T^{*}$ period punishment phase ends in period $t-3$ (and therefore given Lemma $\left.7 T^{*} \geq 3\right)$ This requires $x_{t-\left(T^{*}+3\right)}=C$ and $\tilde{M}_{t-\left(T^{*}+3\right)}=L$ which occurs with probability:

$$
C_{t-\left(T^{*}+3\right)} B^{*}
$$

- AND demand was high in periods $t-1$ and $t-2$. Similar to ii), Bayes rule can be used to obtain the probability $\tilde{M}_{t-1}=H$ given that the necessary condition in Lemma 7 holds:

$$
1-\left(\frac{\left(1-\left(1-B^{*}\right)^{2}\right)}{\left(1-\left(1-B^{*}\right)^{T^{*}}\right)}\right)
$$


Combining (33) and (34), iii) occurs with probability:

$$
\left(C_{t-\left(T^{*}+3\right)} B^{*}\right)\left(1-\left(\frac{\left(1-\left(1-B^{*}\right)^{2}\right)}{\left(1-\left(1-B^{*}\right)^{T^{*}}\right)}\right)\right)
$$

and so on until:

iv. OR,

- a $T^{*}$ period punishment phase ends in period $t-T^{*}$. This requires $x_{t-\left(2 T^{*}\right)}=C$ and $\tilde{M}_{t-\left(2 T^{*}\right)}=L$ which occurs with probability:

$$
C_{t-\left(2 T^{*}\right)} B^{*}
$$

- AND demand was high in periods $t-1$ and $t-2, \ldots$ and $\boldsymbol{t}-\left(\boldsymbol{T}^{*}-\mathbf{1}\right)$. Similar to ii), Bayes rule can be used to obtain the probability $\tilde{M}_{t\left(T^{*}-1\right)}=H$ given that the necessary condition in Lemma 7 holds:

$$
1-\left(\frac{\left(1-\left(1-B^{*}\right)^{T^{*}-1}\right)}{\left(1-\left(1-B^{*}\right)^{T^{*}}\right)}\right)
$$

Combining (36) and (37), iv) occurs with probability:

$$
\left(C_{t-\left(2 T^{*}\right)} B^{*}\right)\left(1-\left(\frac{\left(1-\left(1-B^{*}\right)^{T^{*}-1}\right)}{\left(1-\left(1-B^{*}\right)^{T^{*}}\right)}\right)\right)
$$

If a $T^{*}$ period punishment phase ends in period $t-\left(T^{*}+1\right)$ then $t-T^{*}$ will be collusive $\left(x_{t-T^{*}}=C\right)$ and therefore the possibility of reverting to a punishment phase depends upon low demand occurring in subsequent periods i.e. the condition provided in Lemma 7 is sufficient.

Therefore, using (29), (32), (35), (38) and Lemma 7 we can write the 
probability that period $t$ is a punishment period $\left(1-C_{t}\right)$ as:

$$
\begin{aligned}
1-C_{t}= & \gamma\left(1-C_{t} B^{*}-\left(C_{t-\left(T^{*}+2\right)} B^{*}\right)\left(1-\frac{B^{*}}{\gamma}\right)\right. \\
& -\left(C_{t-\left(T^{*}+3\right)} B^{*}\right)\left(1-\frac{\left(1-\left(1-B^{*}\right)^{2}\right)}{\gamma}\right) \\
& \left.-\ldots \ldots \ldots-\left(C_{t-\left(2 T^{*}\right)} B^{*}\right)\left(1-\frac{\left(1-\left(1-B^{*}\right)^{T^{*}-1}\right)}{\gamma}\right)\right)
\end{aligned}
$$

where $\gamma=1-\left(1-B^{*}\right)^{T^{*}}$

Since $C_{t}$ can be shown to be convergent ${ }^{40}$, we can rewrite (39) as:

$$
\begin{aligned}
1-C_{t}= & \gamma\left(1-C_{t} B^{*}-\left(C_{t} B^{*}\right)\left(1-\frac{B^{*}}{\gamma}\right)\right. \\
& -\left(C_{t} B^{*}\right)\left(1-\frac{\left(1-\left(1-B^{*}\right)^{2}\right)}{\gamma}\right) \\
& \left.-\ldots \ldots-\left(C_{t} B^{*}\right)\left(1-\frac{\left(1-\left(1-B^{*}\right)^{T^{*}-1}\right)}{\gamma}\right)\right)
\end{aligned}
$$

Rearranging (40) gives:

$$
C_{t}=(1-\gamma) /\left(1-B^{*}+T^{*} B^{*}(1-\gamma)-B^{*} \sum_{i=1}^{T^{*}-1}\left(1-B^{*}\right)^{i}\right)
$$

Finally, substituting in for $\gamma=1-\left(1-B^{*}\right)^{T^{*}}$ gives:

Proposition 5. The probability that period $t$ is collusive is given by:

$$
C_{t}=\left(1-B^{*}\right)^{T^{*}} /\left(\left(1-B^{*}\right)+T^{*} B^{*}\left(1-B^{*}\right)^{T^{*}}-B^{*} \sum_{i=1}^{T^{*}-1}\left(1-B^{*}\right)^{i}\right)
$$

\section{The impact of a change in the common discount rate}

Table 2 shows the effect of varying the assumed common discount rate $(\delta)$ set at 0.9 for the results in section 5.2. The size of demand fluctuations $(\underline{u})$ such

\footnotetext{
${ }^{40}$ This can be shown (proof available on request) for $T^{*}=1,2,3$ using Schur's theorem (see Chiang pp. 601-3) and for higher values of $T^{*}$ by simulation.
} 
that breakdowns in collusive behaviour are possible $\left(B^{*}>0\right)$ depends only on collusive sales and the maximum sales possible following a rival deviation (see equation (3) in section 4.2) and therefore is independent of $\delta$. In contrast, a lower $\delta$ increases the short-term gains from deviating and forgoing future collusive profits. This means that collusion is sustainable only if it is less likely to breakdown i.e. $B^{\max }$ falls. Consequently, a lower $\delta$ reduces the range of values for $u$ for which partial collusion occurs ( $\bar{u}$ falls). As the value of $\delta$ falls and approaches the value obtained by Compte et al. (2002) with no demand uncertainty and $T^{*}=\infty$ (see Table 1 ), no partial collusion occurs $\left(B^{\max }=0\right)$. For values of $\delta$ below this level, even with no breakdowns, there is no length of punishment for which collusion is sustainable. 
Table 2: Demand fluctuations for which collusion is sustainable (alternative discount rates)

\begin{tabular}{|c|c|c|}
\hline Outcome & $\underline{u}$ & $\bar{u}$ \\
\hline & $\delta=0.95$ & \\
\hline Pre & 433 & 617 \\
\hline Post & 293 & 327 \\
\hline Remedy 1 & 3292 & 4676 \\
\hline \multirow[t]{2}{*}{ Remedy 2} & 1104 & 1508 \\
\hline & $\delta=0.9($ as in section 5.2$)$ & \\
\hline Pre & 433 & 589 \\
\hline Post & 293 & 313 \\
\hline Remedy 1 & 3292 & 4526 \\
\hline \multirow[t]{2}{*}{ Remedy 2} & 1104 & 1439 \\
\hline & $\delta=0.8$ & \\
\hline Pre & 433 & 532 \\
\hline Post & / & 184 \\
\hline Remedy 1 & 3292 & 4222 \\
\hline \multirow[t]{2}{*}{ Remedy 2} & 1104 & 1298 \\
\hline & $\delta=0.7$ & \\
\hline Pre & 433 & 473 \\
\hline Post & & \\
\hline Remedy 1 & 3292 & 3896 \\
\hline \multirow[t]{2}{*}{ Remedy 2} & 1104 & 1154 \\
\hline & $\delta=0.6$ & \\
\hline Pre & 69 & / \\
\hline Post & & \\
\hline Remedy 1 & 3292 & 3544 \\
\hline \multirow[t]{2}{*}{ Remedy 2} & & \\
\hline & $\delta=0.5$ & \\
\hline Pre & & \\
\hline Post & & \\
\hline Remedy 1 & 0 & / \\
\hline Remedy 2 & 46 & \\
\hline
\end{tabular}


Secondly, Figure 6 reproduces Figures 1 and 4, showing the consumer surplus resulting from collusive behaviour as the size of potential demand fluctuations increases. Here, the lines continue only up to the value of $u$ for which collusive behaviour occurs (i.e. up to $\bar{u}$ as stated in the final column of the previous table) and in each case the bold line represents $\delta=0.9$ as used in section 5.2. Lower values of $\delta$ require longer punishment phases for collusion to be sustainable and thus increase consumer surplus. Therefore the lines further to the left ${ }^{41}$ correspond to increasingly low values of $\delta$.

\footnotetext{
${ }^{41}$ Since $T^{*}$ is discrete and we therefore round up to the nearest whole number satisfying Proposition 4, consumer surplus can be identical for similar values of $\delta$.
} 
Figure 6: Collusive behaviour (alternative discount rates)

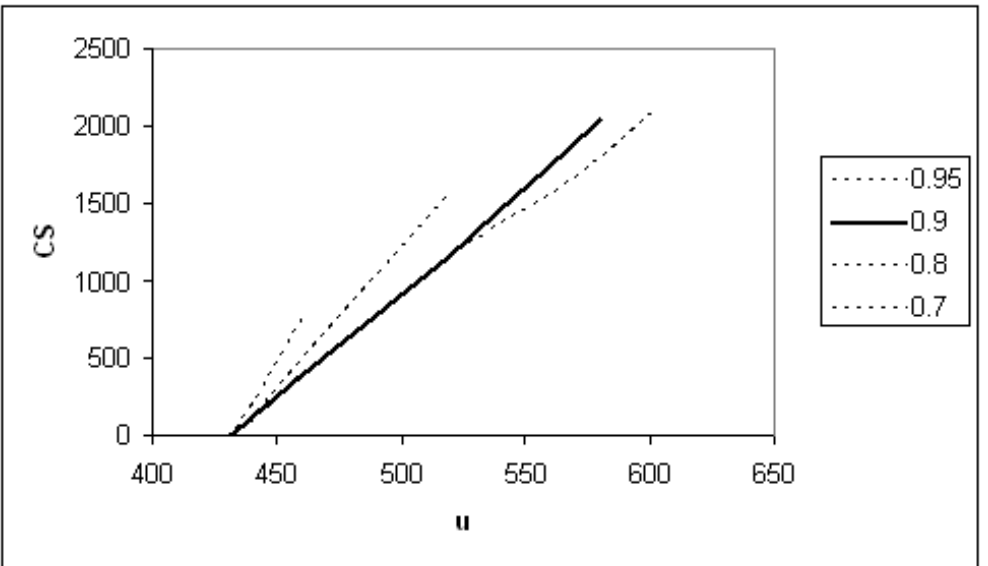

(a) Pre-merger

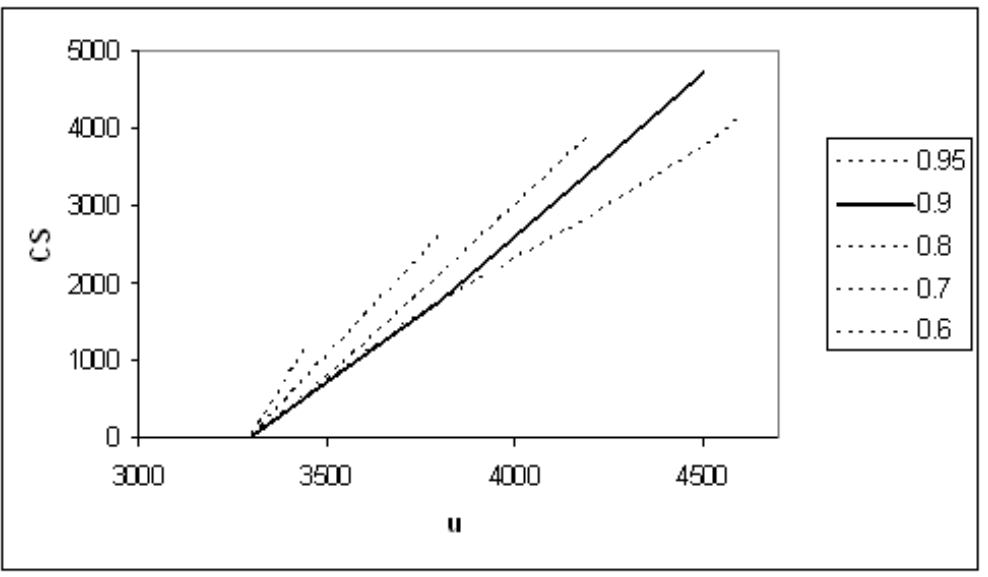

(b) Remedy 1

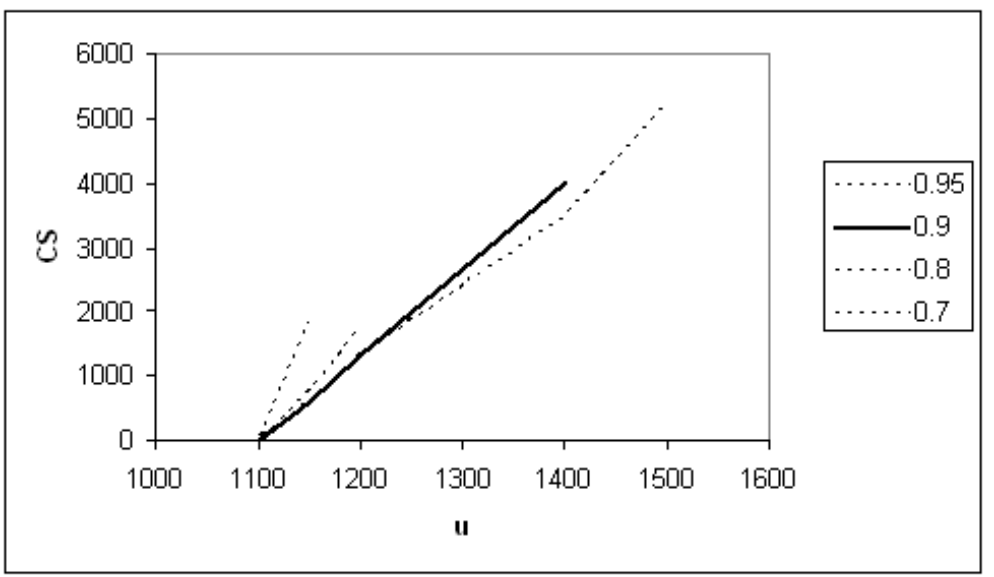

(c) Remedy 2 
These three figures suggest that, for a fixed level of $u$, varying $\delta$ changes the precise level of consumer surplus by a relatively small amount. In contrast, the more significant effect is on precisely the range of values of $u$ for which partial collusion is possible. Consequently, assuming a relatively high value for $\delta$ as in section 5.2, allows maximal scope for partial collusion and provides a lower bound on the predicted consumer surplus.

\section{References}

Chiang, A. C. (1984). Fundamental Methods of Mathematical Economics. McGraw-Hill, 3rd edition.

Church, J. and Ware, R. (2000). Industrial Organisation: A Strategic Approach. McGraw-Hill.

Compte, O., Jenny, F., and Rey, P. (2002). Capacity constraints, mergers and collusion. European Economic Review, 46(1):1-29.

Dasgupta, P. and Maskin, E. (1986a). The existence of equilibrium in discontinuous economic games, I: theory. Review of Economic Studies, 53(1):126.

Dasgupta, P. and Maskin, E. (1986b). The existence of equilibrium in discontinuous economic games, II: applications. Review of Economic Studies, $53(1): 27-41$.

Davies, S. W. and Olczak, M. (2008). Assessing the efficacy of structural merger remedies: choosing between theories of harm? CCP Working Paper, 08-28.

Davis, P. (2006). Coordinated effects merger simulation with linear demands. Competition Commission Working Paper. http://www . competitioncommission.org.uk/our_role/analysis/ coordinated_effects_merger_sim.pdf. 
Fonseca, M. and Normann, H.-T. (2008). Mergers asymmetries and collusion: experimental evidence. Economic Journal, 118(1):287-400.

Gal-Or, E. (1984). Price dispersion with uncertain demand. International Economic Review, 25(2):441-57.

Green, E. and Porter, R. (1984). Non-cooperative collusion under imperfect price information. Econometrica, 52:87-100.

Harrington, J. E. J. (2006). How do cartels operate? Foundations and Trends in Microeconomics, 2(1):1-105. http://www.econ.jhu.edu/ People/Harrington/fnt06.pdf.

Hikisch, S. (2008). Unilateral and coordinated effects merger simulation with non-linear demands. Working Paper. http://esnie.u-paris10.fr/fr/ journees-dates/ESNIE4_Hikisch.pdf.

Hviid, M. (1991). Capacity constrained duopolies, uncertain demand and non-existence of pure strategy equilibria. European Journal of Political Economy, 7:183-90.

Ivaldi, M., Jullien, B., Rey, P., Seabright, P., and Tirole, J. (2003a). The Economics of tacit collusion. Report for DG Comp, European Commission.

Ivaldi, M., Jullien, B., Rey, P., Seabright, P., and Tirole, J. (2003b). The Economics of unilateral effects. Report for DG Comp, European Commission.

Kühn, K.-U. (2004). The co-ordinated effects of mergers in differentiated products markets. University of Michigan Legal Working Paper Series, 34.

Motta, M., Polo, M., and Vasconcelos, H. (2003). Merger remedies in the European Union: an overview. In Lévêque, F. and Shelanski, H., editors, Merger Remedies in American and European Union Competition Law, pages 106-28. Edward Elgar. 
Nevo, A. (2000). Mergers with differentiated products: the case of the readyto-eat cereal industry. RAND Journal of Economics, 31(3):395-421.

Röller, L.-H. and Mano, M. (2006). The impact of the new substantive test in European merger control. European Competition Journal, 2(1):9-28.

Sabbatini, P. (2006). How to simulate the coordinated effect of a merger. Working Paper. http://www.agcm.it/agcm ITA/pubblic/temi . NSF/171CA11D9D9A47D5C12564D0003ED8D8/ OF75C7693321EE79C125719400327CF2/\$FILE/Tp012.pdf.

Tirole, J. (1988). The Theory of Industrial Organisation. MIT Press.

Vives, X. (1999). Oligopoly Pricing. MIT Press.

Werden, G. and Froeb, L. (1994). The effects of mergers in differentiated products industries: logit demand and merger policy. Journal of Law, Economics and Organization, 10(2):407-26. 